\title{
GLANDES INSCRIPTAE PROCEDENTES DE LA HISPANIA ULTERIOR
}

\author{
POR \\ FRANCISCO PINA POLO \\ Universidad Zaragoza \\ WERNER ZANIER \\ Bayerische Akademie der Wissenschaften, München
}

\section{RESUMEN}

Se presenta el catálogo de 49 glandes pertenecientes a un coleccionista privado. Los proyectiles proceden supuestamente del entorno del "Cerro de las Balas" (provincia de Sevilla), junto al cual se supone que tuvo lugar la batalla de Munda en el año 45 a.C. Del total de las piezas, 46 presentan inscripciones, CNMAG; LXIII; A; DD, que son interpretadas respectivamente como Cn(aeus) Mag(nus), L(egio) XIII, A (?) e, hipotéticamente, $d$ (ecreto) d(ecurionum).

\section{SUMMARY}

The paper deals with a collection of 49 glandes which belong to a private collector. These slingshots are supposed to have been found around the so-called "Cerro de las Balas" (province Seville), where the battle of Munda took presumably place in 45 BC. Forty-six of them have inscriptions, CNMAG; LXIII; $A ; D D$, which are respectively interpreted as $C n($ aeus $) \operatorname{Mag}($ nus $), L$ (egio) XIII, A (?) and, tentatively, d(ecreto) d(ecurionum).

PALABRAS CLAVE: Glandes romanas con inscripción; bellum Hispaniense; batalla de Munda.

KEYWORDS: Roman slingshots with inscription; bellum Hispaniense; battle of Munda.

\section{CONTEXTO DEL HALLAZGO}

En el verano del año 2005, un coleccionista de Munich nos hizo llegar cuarenta y nueve glandes procedentes de España con el fin de realizar sobre ellas una investigación.

\footnotetext{
1 Véase al respecto el reciente corpus de glandes inscriptae hispanas publicado por B. Díaz Ariño, "Glandes inscriptae de la Península Ibérica", ZPE 153, 2005, 219-236, en el que el autor recoge un total de 95 proyectiles con inscripción. En particular sobre las glandes con inscripción procedentes de la guerra entre cesarianos y pompeyanos, A.U. Stylow, "Fuentes epigráficas para la historia de la Hispania Ulterior en época republicana", en E. Melchor Gil - J. Mellado Rodríguez - J.F. Rodríguez Neila (eds.), Julio César y Corduba: tiempo y espacio en la campaña de Munda (49-45 a.C.), Córdoba 2005, 247-262, esp. 257-258 y 262. También recientemente se ha publicado un conjunto de unas quinientas glandes conservadas en el Museo Arqueológico de Lorca, de las que sólo un proyectil tiene inscripción, en concreto una letra $\mathrm{N}$ incisa: $\mathrm{S}$. Fontenla Ballesta,
}

Las piezas fueron adquiridas en el verano de 1999 o del año 2000 en un mercado de anticuarios en Sevilla, a través de un único comerciante que le aseguró al coleccionista que procedían todas ellas del entorno del denominado Cerro de las Balas, en la parte oriental de la provincia de Sevilla. De ellas, cuarenta y seis portan inscripciones, mientras que las tres restantes son anepígrafas. Las glandes inscriptae que se dan a conocer en este trabajo suponen, por consiguiente, un aporte significativo respecto a los proyectiles hispanos con inscripción publicados hasta ahora ${ }^{1}$.

Se trata obviamente de piezas que no proceden de una excavación arqueológica, sino de búsquedas llevadas a cabo por clandestinos, algo que evidentemente dificulta su estudio y su interpretación histórica. Unido a la irregularidad de su procedencia está el problema de la autenticidad de este tipo de materiales arqueológicos, no siempre fácil de determinar con absoluta seguridad, incluso mediante análisis químicos, dada la posibilidad de reutilización de plomo antiguo. Puede parecer sorprendente a primera vista la elevada cantidad de glandes de plomo existentes en el mercado del coleccionismo y de las antigüedades. Sin duda pueden existir falsificaciones, pero no hay tampoco que olvidar que son elementos que pueden conservarse largamente por el material en el que están fabricados, y que, en ocasiones determinadas, como debió de suceder en una batalla como la de Munda - en cuyo contexto hay que inscribir al parecer los proyectiles objeto de estudio -, en la que se vieron involucrados miles de soldados, su uso pudo ser masivo ${ }^{2}$. Por otra parte, la fecha de adquisición de

"Glandes de honda procedentes de la batalla de Asso", Alberca: Revista de la Asociación de Amigos del Museo Arqueológico de Lorca 3, 2005, 67-84.

2 En referencia a los proyectiles procedentes del sitio de Perusia, afirma L.J.F. Keppie, The Making of the Roman Army. From Republic to Empire, Totowa N.J. 1984, 123-125: "The bullets... must have been made by the million". En Hispania, además de los quinientos proyectiles conservados en el Museo de Lorca (véase n.1), se han encontrado recientemente en el campamento de Andagoste setenta y siete glandes anepígrafas: J.A. Ocharan Larrondo - M. Unzueta Portilla, "Andagoste (Cuartango, Álava): un nuevo escenario de las guerras de conquista en el Norte de Hispania”, en Á. Morillo (ed.), Arqueología militar romana en Hispania, Anejos de Gladius 5, Madrid 2002, 311-325. 
los proyectiles objeto de este estudio, 1999 o 2000, es más bien un argumento en contra de que puedan tratarse de falsificaciones, puesto que éstas sólo en los dos o tres últimos años han aumentado al parecer de valor al crecer la demanda de glandes con inscripción.

\section{FORMAS, TÉCNICAS DE FABRICACIÓN E INSCRIPCIONES}

Entre los proyectiles que se estudian en este trabajo, se distinguen cuatro grupos diferentes de acuerdo con las inscripciones: 1. Cn(aeus) Mag(nus), con trece ejemplares; 2. L(egio) XIII, con cinco; 3. A, con nueve; 4. $d(-) d(-)$, con diecinueve, junto con los tres sin inscripción ${ }^{3}$.

\section{Grupo 1: Cn(aeus) Mag(nus)}

Los trece proyectiles con la inscripción Cn(aeus) Mag(nus) tienen una forma más bien aplanada en la parte inferior, aunque la mayoría de ellos con una cierta tendencia convexa. La inscripción se encuentra en la parte superior, de forma cónica. Debieron de ser fabricados en un molde de fundición univalvo de arcilla con letras rehundidas. El molde general debía de estar formado por una serie de moldes individuales para cada pieza, de manera que pudieran ser fundidos al mismo tiempo varios proyectiles. Las diferentes piezas estaban unidas entre sí en sus lados longitudinales a través de canalillos de fundición, que serían posteriormente eliminados. En el caso de que fuera vertida una excesiva cantidad de plomo en uno de los moldes, podían formarse rebabas de fundición en la parte inferior de los proyectiles, tal y como sucede en muchos de los que aquí presentamos. Las glandes del Grupo 1 pesan entre 44,6 y 90,9 gramos, con una mayor concentración en torno a los 80 gramos.

\section{Grupo 2: L(egio) XIII}

Los cinco proyectiles con la inscripción L(egio) XIII fueron fabricados con la misma técnica que los del Grupo 1, y presentan formas semejantes. Son sin embargo más ligeros, puesto que pesan entre 34,9 y 42 gramos, con excepción de un ejemplar de 62,4 gramos.

\footnotetext{
3 En un catálogo de subastas del año 2001 (Gorny \& Mosch. Giessener Münzhandlung. Auktion 111. Kunstobjekte der Antike, München 2001, 119, n 3567 y 3568) aparecían referenciadas ocho glandes, de las cuales no se daba noticia de su origen, que corresponden exactamente a los cuatro grupos que se recogen en este artículo: tres con las inscripción CNMAG, uno con LXIII, uno con A, y finalmente tres con DD. Con toda probabilidad tienen la misma procedencia que las que aquí presentamos (véase addendum).
}

\section{Grupo 3: A}

En nueve proyectiles aparece solamente la letra $A$. Su técnica de fabricación es idéntica a las de los Grupos 1 y 2 , y sus formas similares. Su peso se aproxima más bien al de las piezas del Grupo 2, entre 22,2 y 58,7 gramos, con una mayor concentración entre 40 y 45 gramos.

Grupo 4: d(-) d(-)

Los diecinueve proyectiles con la leyenda $d(-)$ $d(-)$ se corresponden en sus formas con las más habituales entre las glandes conocidas hasta ahora. La mayoría de ejemplares (números 28-43) pertenecen a los tipos I y II de Völling, respectivamente de forma ovoide y bicónica ${ }^{4}$. Una diferenciación de las variantes dentro de ambos tipos resulta por regla general difícil de establecer. Las puntas claramente planas del proyectil numero 44 corresponden al tipo IV de Völling, mientras que los ejemplares 45 y 46 , con forma de doble pirámide, pertenecen a su tipo III. Todos fueron fabricados mediante moldes de fundición bivalvos, y tienen la particularidad de que, tras su fundición, la inscripción $d(-) d(-)$ fue estampada mediante un sello. La leyenda $d(-) d(-)$ aparece enmarcada dentro de una cartela de $0,7 / 0,8 \times 0,4 / 0,5 \mathrm{~cm}$ de tamaño. El peso de estas glandes oscila entre 23,8 y 103,2 gramos, la mayoría de ellas entre 38 y 58 gramos. La gran diferencia de peso puede tal vez explicarse a través de la afirmación de Estrabón al hablar de los famosos honderos baleáricos, de acuerdo con la cual el peso podría variar según el uso de los proyectiles, para larga, mediana o corta distancia ${ }^{5}$.

Los tres primeros grupos constituyen por consiguiente una unidad debido tanto a su técnica de fabricación como a sus formas: todos fueron fabricados en un molde de fundición univalvo y las inscripciones fueron realizadas al mismo tiempo que las glandes eran fundidas. De ellos se distingue claramente el Grupo 4, puesto que tales proyectiles tienen las formas habituales de las glandes conocidas, fueron fabricados en moldes bivalvos, y sólo tras la fundición fueron estampadas las letras $d(-) d(-)$ en cada ejemplar mediante un sello. En la mayoría de las glandes inscriptae conocidas, la inscripción es fundida junto con el proyectil, pero exis-

4 Th. Völling, "Funditores im römischen Heer", Saalburg Jahrbuch, 45, 1990, 24-58 (incluyendo una lista de glandes conocidas en todo el imperio romano). Véase asimismo la recopilación y diferenciación tipológica de glandes procedentes de la Galia Transalpina en P. Arnaud - D. Boisse - J. Gautier, "Balles de fronde antiques en plomb du pays Salluvien, Cavare et Voconce (Rhône)", Instrumentum 9 (1999) 26-28.

5 Str., III 5, 1 . 
ten asimismo ejemplos de inscripciones realizadas con un sello ${ }^{6}$.

Llama la atención el hecho de que buena parte de las glandes no tengan la habitual forma bicónica u ovoide, sino que sean más bien aplanadas en el lado contrario al que aparece la inscripción. Éste es un hecho extraordinario, pero existen algunos paralelos ${ }^{7}$. Estos proyectiles podrían tener por su forma pequeñas desventajas desde el punto de vista de la balística - en el caso de que realmente las tuvieran ${ }^{8}$ - en comparación con los habituales ejemplares de forma bicónica u ovoide, lo cual puede posiblemente explicarse por una rápida fabricación, puesto que tendría sentido una producción apresurada de glandes como preparación de una probable batalla que hubiera de tener lugar de manera inmediata. Es sabido que las glandes eran fundidas por el mismo ejército en campaña ${ }^{9}$, y la arqueología experimental ha demostrado que la fabricación era sencilla, pero que llevaba a las piezas a adoptar formas extrañas en caso de emergencia $^{10}$

$6 \mathrm{Se}$ conocen glandes con inscripción sellada pertenecientes a las legiones III, X y XII, procedentes de Crap Ses-Schlucht y del Septimerpass, en el cantón suizo de Graubünden: J. Rageth, "Frührömische Militaria aus dem Oberhalbstein GR - Belege für den Alpenfeldzug?", Jahrbuch der Schweizerischen Gesellschaft für Ur- und Frühgeschichte 87, 2004, 297-303; esp.297 Lám.1; 298 Lám.3; 299 Lám.4,2.811; 301 Lám.6; J. Rageth, "Weitere frührömische Militaria und andere Funde aus dem Oberhalbstein GR - Belege für den Alpenfeldzug", Jahrbuch der Schweizerischen Gesellschaft für Ur- und Frühgeschichte 88, 2005, 302-312, esp.204 Lám. 2,4.9-12; 306 Lám.4-6; 308 Lám. 8,1-7; 311 Lám.10 y 11.

7 En la recopilación de glandes inscriptae llevada a cabo por C. Zangemeister, Glandes plumbeae latine inscriptae, Ephemeris Epigraphica 6, Roma-Berlin 1885, se recogen al menos dos proyectiles con una de las partes plana, la otra con inscripción (n ${ }^{\circ} 18$ y 42).

8 D. Baatz, "Schleudergeschosse aus Blei - eine waffentechnische Untersuchung", Saalburg Jahrbücher, 45, 1990, 5967, esp.67.

9 Caes., bell.Afr., 20.

${ }^{10}$ Véase al respecto A.V.A.J. Bosman, "Pouring lead in the pouring rain: making lead slingshot under battle condition", JRMES 6, 1995, 99-103, esp.101: "the shape of the leaden shot does not matter at all". Se ha encontrado un interesante ejemplo del modo de fabricación de glandes en moldes de arcilla en el yacimiento de La Caridad (Caminreal, Teruel), donde se han hallado proyectiles procedentes del molde de fundición, unidos todavía unos a otros (J. Vicente - Mª P. Punter - B. Ezquerra, "La catapulta tardo-republicana y otro equipamiento militar de 'La Caridad' (Caminreal, Teruel)”, JRMES 8, 1997, 190 y 195. Véase asimismo un molde para la fabricación de glandes con inscripción EVLG en M. Poux - L. Guyard, "Un moule à balles de fronde inscrit d'époque tardo-républicaine à Paris (rue Saint-Martin)”, Instrumentum 9 (1999) 29-30.

\section{CATÁlOGO}

GRUPO 1: Cn(aeus) Mag(nus) (Figuras 1 y 6)

1. Superficie blanquecina, marrón clara, gris oscura. Dimensiones: longitud: $4,6 \mathrm{~cm}$; anchura: $2,4 \mathrm{~cm}$; altura: $1,8 \mathrm{~cm}$. Peso: 90,9 gr. Inscripción en la parte superior: CnMag

2. Superficie blanquecina, marrón clara, gris oscura. Dimensiones: longitud: $5,3 \mathrm{~cm}$; anchura: $2,3 \mathrm{~cm}$; altura: 1,8 cm. Peso: 82 gr. Inscripción en la parte superior: $\mathrm{CnMag}$

3. Uno de los lados longitudinales presenta una hendidura semicircular. Superficie blanquecina, gris oscura. Dimensiones: longitud: 4,6 cm; anchura: 2,4 cm; altura: 1,7 cm. Peso: 81,8 gr. Inscripción en la parte superior: [C]nMag

4. Superficie blanquecina, marrón clara. Dimensiones: longitud: 4,5 cm; anchura: $2,5 \mathrm{~cm}$; altura: 1,8 cm. Peso: 81,3 gr. Inscripción en la parte superior: CnMag

5. Ambos extremos recortados, con puntas planas. Superficie marrón clara. Dimensiones: longitud: 5 cm; anchura: 1,9 cm; altura: 1,9 cm. Peso: 77,6 gr. Inscripción en la parte superior: CnMag

6. Superficie marrón clara, blanquecina. Dimensiones: longitud: 5,4 cm; anchura: $2 \mathrm{~cm}$; altura: $1,5 \mathrm{~cm}$. Peso: 71,5 gr. Inscripción en la parte superior: CnMag

7. Superficie blanquecina, gris oscura. Dimensiones: longitud: 4,8 cm; anchura: $2,1 \mathrm{~cm}$; altura: $1,6 \mathrm{~cm}$. Peso: 66,4 gr. Inscripción en la parte superior: CnMag

8. Superficie blanquecina, marrón clara, marrón oscura. Dimensiones: longitud: $5 \mathrm{~cm}$; anchura: $2,3 \mathrm{~cm}$; altura: 1,5 cm. Peso: 63,3 gr. Inscripción en la parte superior: CnMag

9. Superficie blanquecina, marrón clara, en parte eliminada (supuestamente por haber sido tratada modernamente con barniz para su fijación). Dimensiones: longitud: $4,2 \mathrm{~cm}$; anchura: $2,2 \mathrm{~cm}$; altura: 1,5 cm. Peso: 58,3 gr. Inscripción en la parte superior: $C n[M] a g$

10. Un lado longitudinal recortado Superficie blanquecina, marrón clara, gris oscura. Dimensiones: longitud: 4,5 cm; anchura: $1,8 \mathrm{~cm}$; altura: $1,5 \mathrm{~cm}$. Peso: 55,5 gr. Inscripción en la parte superior: CnMag

11. Superficie blanquecina, marrón clara; con restos de tierra sobre ella. Dimensiones: longitud: $4,3 \mathrm{~cm}$; anchura: $2 \mathrm{~cm}$; altura: 1,4 cm. Peso: 50,3 gr. Inscripción en la parte superior: CnMag

12. Superficie blanquecina, marrón clara. Dimensiones: longitud: 4,1 cm; anchura: $1,8 \mathrm{~cm}$; altura: $1,4 \mathrm{~cm}$. Peso: 47,4 gr. Inscripción en la parte superior: CnMag

13. Superficie blanquecina. Dimensiones: longitud: 3,9 cm; anchura: 1,8 cm; altura: 1,3 cm. Peso: 44,6 gr. Inscripción en la parte superior: $C n M[a] g$ 


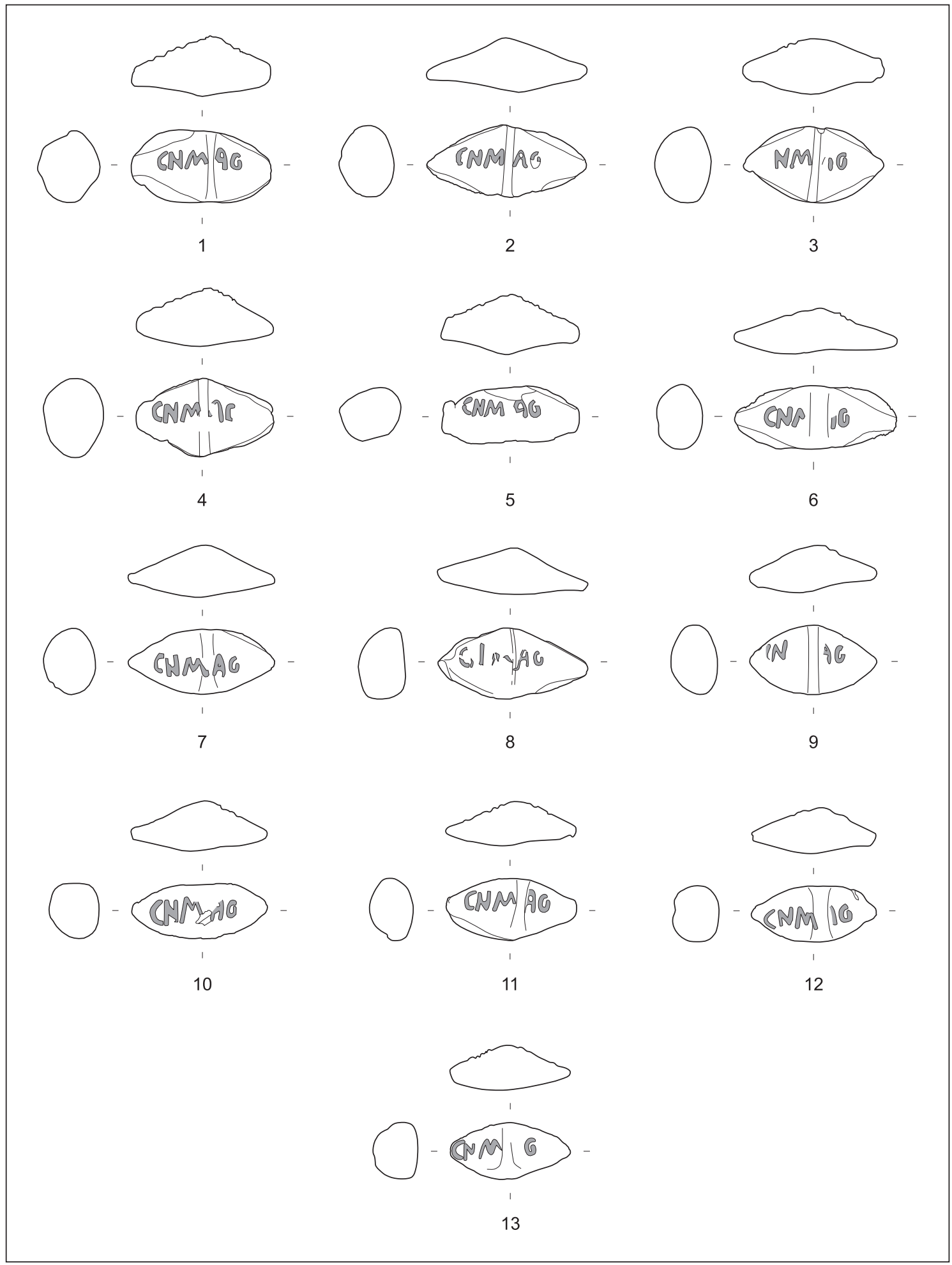

Figura 1. Glandes inscriptae de la Hispania Ulterior. Grupo 1 con inscripción Cn(aeus) Mag(nus). Numeración según el catálogo. Escala 1:2 


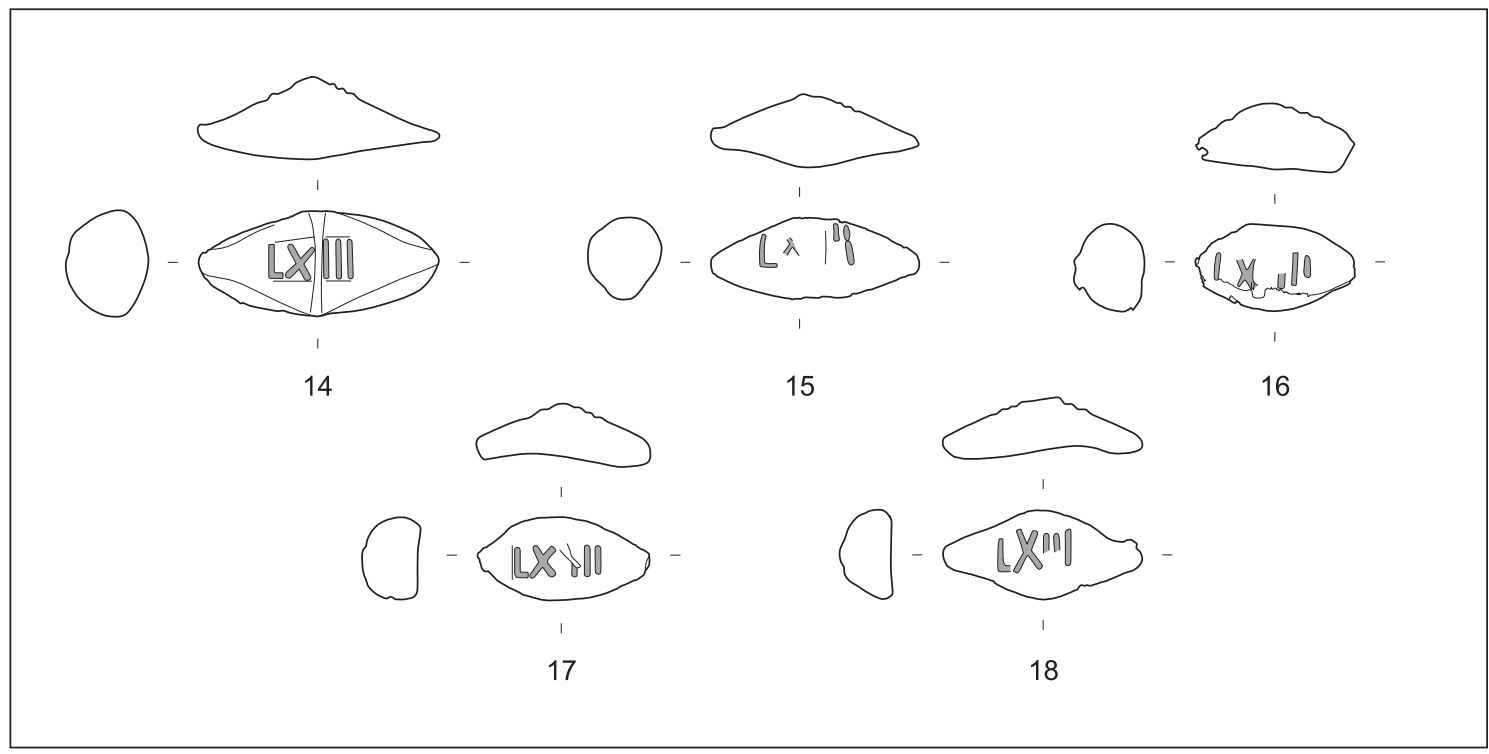

Figura 2. Glandes inscriptae de la Hispania Ulterior. Grupo 2 con inscripción L(egio) XIII. Numeración según el catálogo. Escala 1:2

GRUPO 2: L(egio) XIII (Figuras 2 y 6)

14. Superficie blanquecina, marrón clara. Dimensiones: longitud: $5,1 \mathrm{~cm}$; anchura: $2,1 \mathrm{~cm}$; altura: 1,6 cm. Peso: 62,4 gr. Inscripción en la parte superior aparentemente enmarcada con tenues líneas a modo de cartela: LXIII

15. Superficie gris-blanquecina. Dimensiones: longitud: 4,4 cm; anchura: $1,6 \mathrm{~cm}$; altura: $1,5 \mathrm{~cm}$. Peso: 42 gr. Inscripción en la parte superior de difícil lectura: $L X[I] ! I$

16. Uno de los extremos partido. Superficie blanquecina, desaparecida en algunas partes. Dimensiones: longitud: $3,3 \mathrm{~cm}$; anchura: $1,7 \mathrm{~cm}$; altura: $1,4 \mathrm{~cm}$. Peso: 39,5 gr. Inscripción en la parte superior: LXIII

17. Superficie gris-blanquecina. Dimensiones: longitud: $3,6 \mathrm{~cm}$; anchura: $1,7 \mathrm{~cm}$; altura: $1,3 \mathrm{~cm}$. Peso: 39,4 gr. Inscripción en la parte superior: LXIII

18. Superficie blanquecina, gris oscura. Dimensiones: longitud: 4,2 cm; anchura: $1,8 \mathrm{~cm}$; altura: $1,1 \mathrm{~cm}$. Peso: 34,9 gr. Inscripción en la parte superior: LXIII

GRUPO 3: A (Figuras 3 y 7)

19. Extremos recortados. Superficie blanquecina, gris oscura. Dimensiones: longitud: $3,9 \mathrm{~cm}$; anchura: $1,8 \mathrm{~cm}$; altura: 1,6 cm. Peso: 58,7 gr. Inscripción en la parte superior, desplazada a la izquierda: $A$

20. Superficie blanquecina. Dimensiones: longitud: $4,2 \mathrm{~cm}$; anchura: $2,1 \mathrm{~cm}$; altura: $1,5 \mathrm{~cm}$. Peso: 55,4 gr. Inscripción en la parte superior, desplazada a la izquierda: $A$
21. Superficie blanquecina, marrón clara, gris. Dimensiones: longitud: $3,7 \mathrm{~cm}$; anchura: $1,8 \mathrm{~cm}$; altura: 1,5 cm. Peso: 46,1 gr. Inscripción en la parte superior, desplazada a la izquierda: $A$

22. Rotura antigua en uno de los extremos. Superficie blanquecina, marrón clara, gris. En la parte posterior dos hendiduras verticales. Dimensiones: longitud: 3,5 cm; anchura: 1,9 cm; altura: 1,4 cm. Peso: 44,7 gr. Inscripción en la parte superior, desplazada a la izquierda: $A$

23. Superficie blanquecina, muy blanda. Dimensiones: longitud: 3,2 cm; anchura: $2 \mathrm{~cm}$; altura: $1,6 \mathrm{~cm}$. Peso: 43 gr. Inscripción en la parte superior, desplazada a la izquierda: $A$

24. Superficie blanquecina, marrón clara. Dimensiones: longitud: $3,9 \mathrm{~cm}$; anchura: $1,7 \mathrm{~cm}$; altura: 1,4 cm. Peso: 41,8 gr. Inscripción en la parte superior, desplazada a la izquierda: $A$

25. Superficie blanquecina, gris, con parte en las que hay restos de tierra adherida. Dimensiones: longitud: $3,2 \mathrm{~cm}$; anchura: $1,9 \mathrm{~cm}$; altura: $1,3 \mathrm{~cm}$. Peso: 40,7 gr. Inscripción en la parte superior, desplazada a la izquierda: $A$

26. Superficie blanquecina, marrón clara, gris. Dimensiones: longitud: $2,8 \mathrm{~cm}$; anchura: $1,7 \mathrm{~cm}$; altura: 1,1 cm. Peso: 24,5 gr. Inscripción en la parte superior, desplazada a la izquierda: $A$

27. Superficie blanquecina. Dimensiones: longitud: 3 $\mathrm{cm}$; anchura: 1,7 cm; altura: $1 \mathrm{~cm}$. Peso: 22,2 gr. Inscripción en la parte superior, desplazada a la izquierda: $A$ 


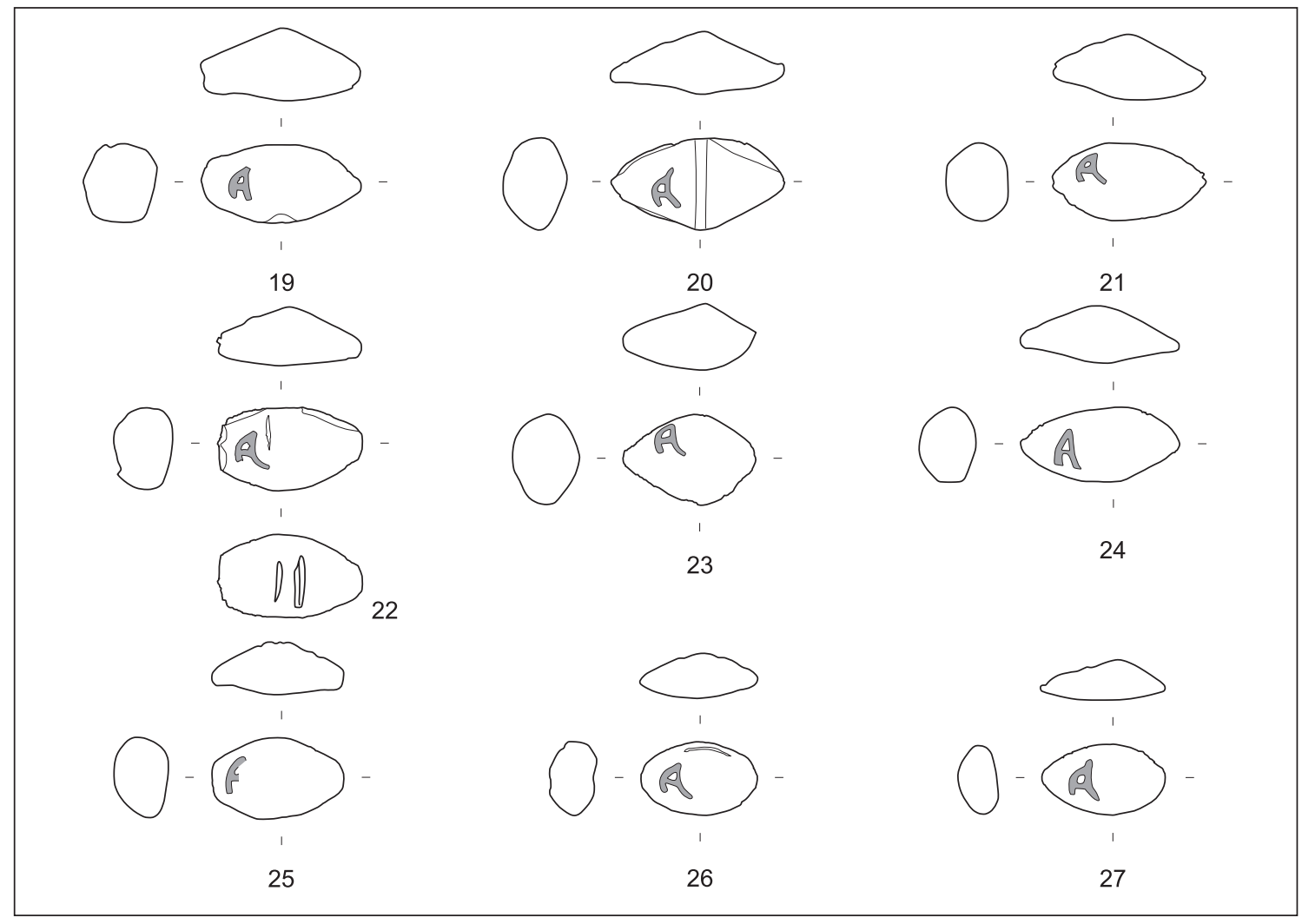

Figura 3. Glandes inscriptae de la Hispania Ulterior. Grupo 3 con inscripción A. Numeración según el catálogo. Escala 1:2

GRUPO 4: $d(-) d($ (一) (Figuras 4, 5, 7 y 8)

28. Superficie irregular, marrón clara, muy dura. Dimensiones: longitud: $4,6 \mathrm{~cm}$; diámetro: $2-2,2$ cm. Peso: 103,2 gr. Cartela enmarcando el sello: 0,8 x $0,5 \mathrm{~cm}$. Inscripción: $d(-) d(-)$

29. Superficie blanquecina y muy blanda. Dimensiones: longitud: 4,3 cm; diámetro: 1,9-2,2 cm. Peso: 79,5 gr. Cartela enmarcando el sello: $0,7 \times 0,5 \mathrm{~cm}$. Inscripción: $d(-) d(-)$

30. Superficie blanquecina. Dimensiones: longitud: 4,2 cm; diámetro: 1,7-1,9 cm. Peso: 68 gr. Cartela enmarcando el sello: $0,8 \times 0,5 \mathrm{~cm}$. Inscripción: $d(-) d(-)$

31. Una punta rota. Superficie blanquecina. Dimensiones: longitud: 3,9 cm; diámetro: 1,7-1,9 cm. Peso: 57,4 gr. Cartela enmarcando el sello: $0,7 \times 0,4 \mathrm{~cm}$. Inscripción: $d(-) d(-)$

32. Superficie irregular, marrón clara, con restos de tierra adherida. Dimensiones: longitud: $3,8 \mathrm{~cm}$; diámetro: 1,7-2,1 cm. Peso: 54,6 gr. Cartela enmarcando el sello: 0,8 x $0,4 \mathrm{~cm}$. Inscripción: $d(-) d(-)$

33. Superficie blanquecina. Dimensiones: longitud: 4,1 cm; diámetro: 1,7-1,8 cm. Peso: 53,2 gr. Cartela enmarcando el sello: 0,8 x $0,5 \mathrm{~cm}$. Inscripción: $d(-) d(-)$
34. Una punta cortada. Superficie blanquecina. gris. Dimensiones: longitud: $4 \mathrm{~cm}$; diámetro: 1,7-1,8 cm. Peso: 52,9 gr. Cartela enmarcando el sello: 0,8 x $0,5 \mathrm{~cm}$. Inscripción: $d(-) d(-)$

35. Superficie deteriorada, blanquecina, gris. Dimensiones: longitud: $4,4 \mathrm{~cm}$; diámetro: $1,7 \mathrm{~cm}$. Peso: 52 gr. Cartela enmarcando el sello: $0,8 \times 0,4 \mathrm{~cm}$. Inscripción: $d(-) d(-)$

36. Superficie irregular, blanquecina, gris. Dimensiones: longitud: 4,1 cm; diámetro: 1,6-1,7 cm. Peso: 46,2 gr. Cartela enmarcando el sello: $0,8 \times 0,5 \mathrm{~cm}$. Inscripción: $d(-) d(-)$

37. Superficie blanquecina, gris. Dimensiones: longitud: 4,2 cm; diámetro: 1,3-1,6 cm. Peso: 43 gr. Cartela enmarcando el sello: 0,5 x 0,5 cm. Inscripción: $d(-) d(-)$

38. Superficie de color violáceo, parcialmente calcificada. Dimensiones: longitud: $3,1 \mathrm{~cm}$; diámetro: 1,6-1,9 cm. Peso: 42,8 gr. Cartela enmarcando el sello: 0,8 x $0,5 \mathrm{~cm}$. Inscripción: $d(-) d(-)$

39. Superficie marrón clara, blanquecina. Dimensiones: longitud: $3 \mathrm{~cm}$; diámetro: 1,7-1,8 cm. Peso: 42,5 gr. Cartela enmarcando el sello: $0,8 \times 0,4 \mathrm{~cm}$. Inscripción: $d(-) d(-)$ 


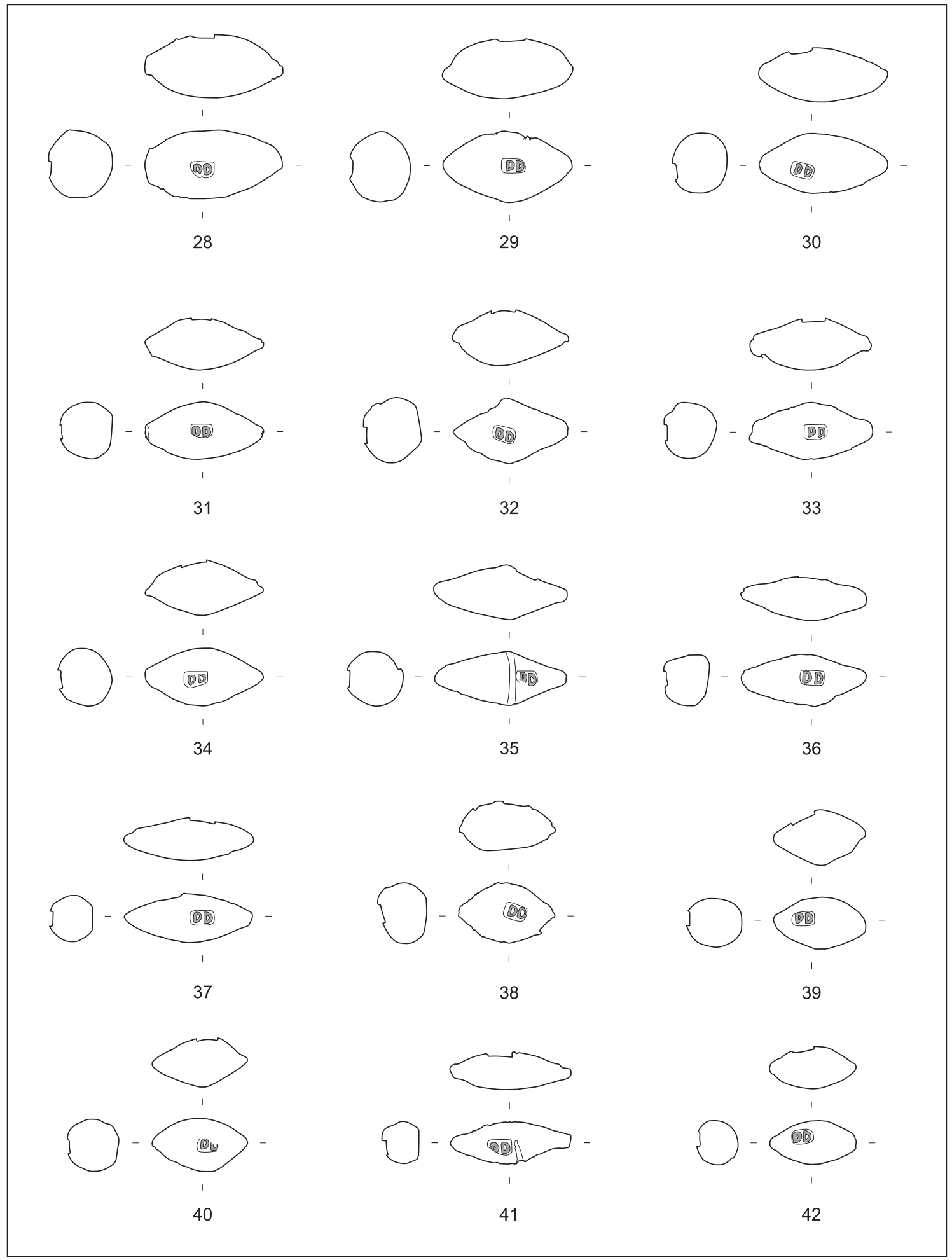

Figura 4. Glandes inscriptae de la Hispania Ulterior. Grupo 4 con sello $d(--) d(--)(28-42)$. Numeración según el catálogo. Escala 1:2 


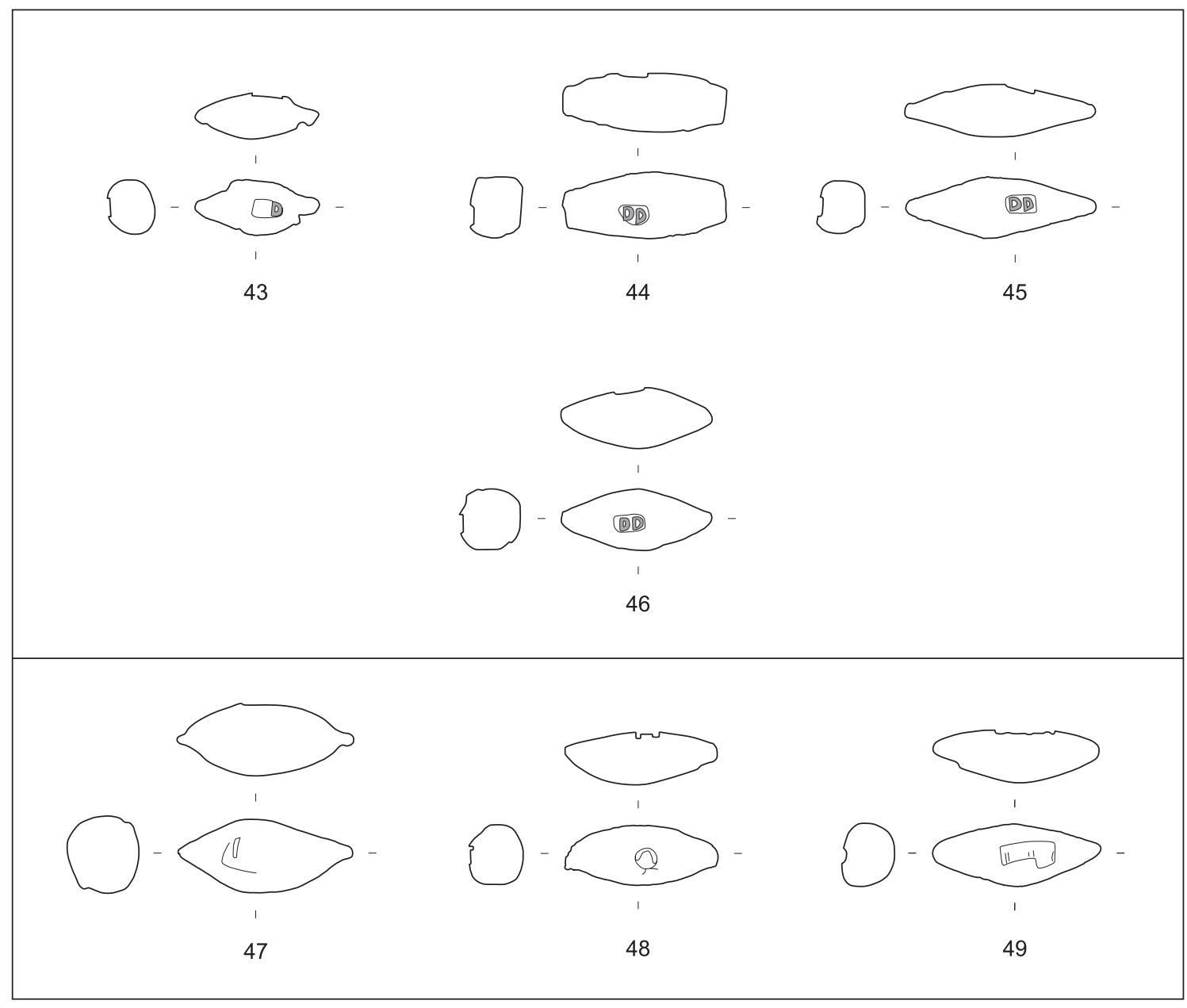

Figura 5. Glandes inscriptae de la Hispania Ulterior. Grupo 4 con sello $d(--) d(--)$ (43-46) y tres ejemplares sin inscripción (47-49). Numeración según el catálogo. Escala 1:2

40. Superficie marrón clara, blanquecina. Dimensiones: longitud: $3,1 \mathrm{~cm}$; diámetro: 1,6-1,7 cm. Peso: 38,9 gr. Cartela enmarcando el sello: $0,7 \times 0,5 \mathrm{~cm}$. Inscripción: $d(-) d(-)$

41. Un lado aplanado (quizás en época moderna) En una hendidura restos de tierra adherida. Una punta plana. Superficie marrón oscura. Dimensiones: longitud: $4 \mathrm{~cm}$; diámetro: 1,2-1,3 cm. Peso: 30,4 gr. Cartela enmarcando el sello: 0,8 x 0,4 cm. Inscripción: $d(-) d(-)$

42. Superficie marrón clara. Dimensiones: longitud: 2,8 cm; diámetro: 1,3-1,4 cm. Peso: 26,8 gr. Cartela enmarcando el sello: $0,7 \times 0,5 \mathrm{~cm}$. Inscripción: $d(-) d(-)$

43. Superficie irregular, con huellas de cortes modernos (?), marrón clara. Dimensiones: longitud: 3,3 cm; diámetro: 1,2-1,4 cm. Peso: 23,8 gr. Cartela enmarcando el sello: 0,7 x 0,5 cm. Inscripción: $[d(-)] d(-)$

44. Puntas planas y corte transversal cuadrangular irregular. Superficie tallada formando ángulos (¿cortada o martillada?), marrón clara y dura. Dimensiones: longitud: 4,3 cm; diámetro: 1,4-1,7 cm. Peso: 64,1 gr. Cartela enmarcando el sello: $0,8 \times 0,4 \mathrm{~cm}$. Inscripción: $d(-) d(-)$

45. Superficie marrón clara. Dimensiones: longitud: 5 cm; diámetro: 1,3-1,7 cm. Peso: 46 gr. Cartela enmarcando el sello: 0,8 x $0,5 \mathrm{~cm}$. Inscripción: $d(-) d(-)$

46. Superficie marrón clara, blanquecina, con restos de tierra adherida. Dimensiones: longitud: 4,1 cm; diámetro: 1,6-1,7 cm. Peso: 45,7 gr. Cartela enmarcando el sello: 0,8 × $0,5 \mathrm{~cm}$. Inscripción: $d(-) d(-)$ 


\section{Grupo 1}

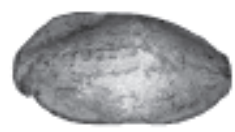

1
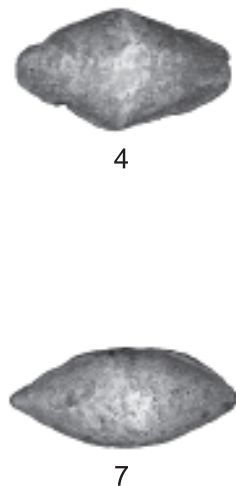

7

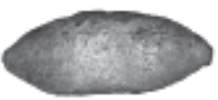

10

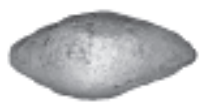

13

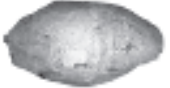

16

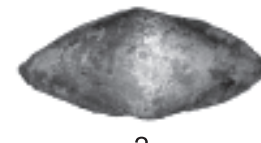

2

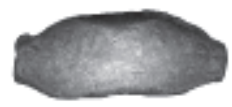

5
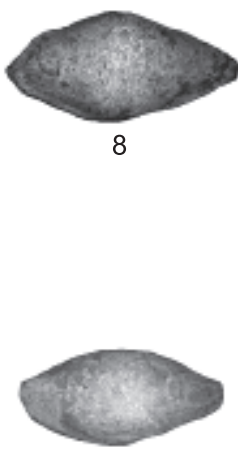

11

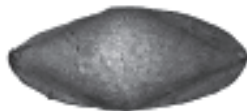

14

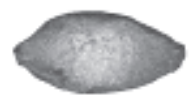

17
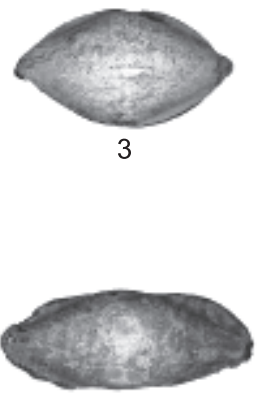

6
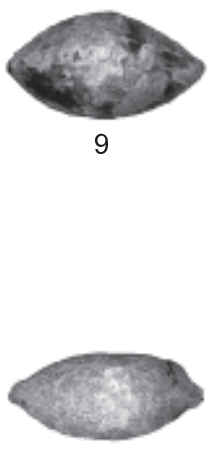

12

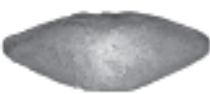

15

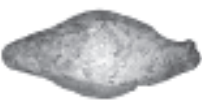

18

\section{Grupo 2}

Figura 6. Glandes inscriptae de la Hispania Ulterior. 1-13 Grupo 1 con inscripción Cn(aeus) Mag(nus) - 14-18 Grupo 2 con inscripción L(egio) XIII. Escala 1:2 


\section{Grupo 3}

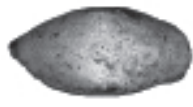

19

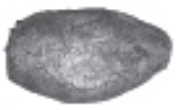

22

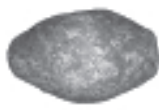

25

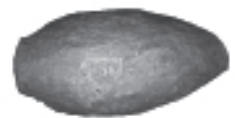

28

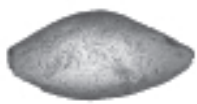

31

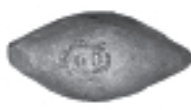

34

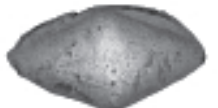

20

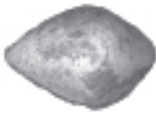

23

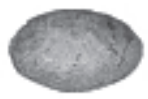

26

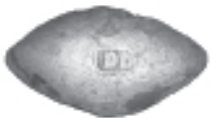

29

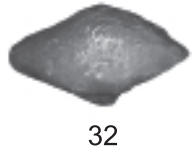

32

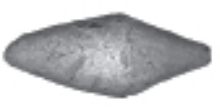

35

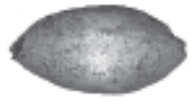

21

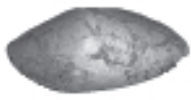

24

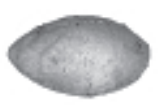

27

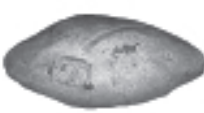

30

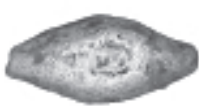

33

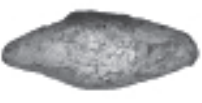

36

\section{Grupo 4}

Figura 7. Glandes inscriptae de la Hispania Ulterior. 19-27 Grupo 3 con inscripción $A$ - 28-36 Grupo 4 con sello $d(--) d(--)$. Escala 1:2 


\section{Grupo 4}

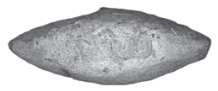

37

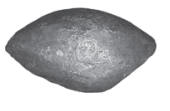

40

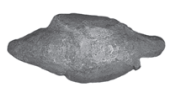

43

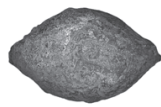

38

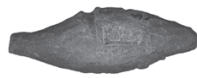

41

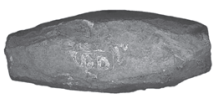

44

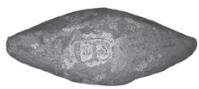

46

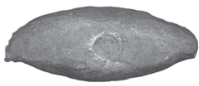

48

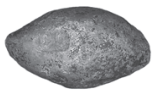

39

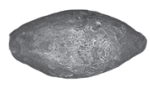

42

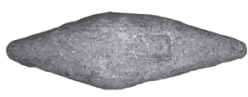

45

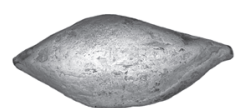

47

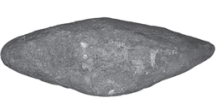

49

\section{sin inscripción}

Figura 8. Glandes inscriptae de la Hispania Ulterior. 37-46 Grupo 4 con sello $d(--) d(--)$ - 47-49 sin inscripción. Escala 1:2

SIN INSCRIPCIÓN (Figuras 5 y 8 )

47. Superficie blanquecina. Dimensiones: longitud: 4,6 cm; diámetro: 1,6-1,8 cm. Peso: 64,7 gr. Sin inscripción.

48. Superficie marrón clara con restos de tierra adherida. En un lado podría existir una letra $(Q$ ?), que no se correspondería con las habituales letras en relieve, sino quizá con un sello ${ }^{11}$. Dimensiones: longitud: $4 \mathrm{~cm}$; diámetro: 1,4-1,6 cm. Peso: 40,4 gr.

49. En la parte inferior, aproximadamente en su sección central, existe un espacio ahondado de 1,5 x $0,5 \mathrm{~cm}$ con superficie irregular. Superficie marrón clara con restos de tierra adherida. Dimensiones: longitud: 4,4 cm; diámetro: 1,3-1,6 cm. Peso: 39,6 gr. Sin inscripción.

${ }^{11}$ Las dos glandes conocidas hasta ahora en la Península Ibérica con inscripción LXIII llevan en la parte posterior un signo semejante al que aparece en el número 48 de nuestro catálogo, que ha sido interpretado como una letra Q. ¿Puede tener nuestra pieza $\mathrm{n}^{\circ} 48$ alguna relación con los proyectiles de la legio XIII? Cf. Díaz Ariño, Glandes inscriptae (cit. n.1), 228, 233 , anexo $\mathrm{n}^{\circ} 58-59$. 


\section{INTERPRETACIÓN HISTÓRICA}

La interpretación histórica de los proyectiles parte condicionada por un problema de muy difícil resolución, cual es su procedencia irregular, algo que, por otra parte, viene siendo habitual en este tipo de materiales metálicos. De acuerdo con las informaciones que obran en nuestro poder, cuando el comprador de los proyectiles los adquirió hace varios años en Sevilla, se le dijo que provenían de las cercanías del denominado Cerro de las Balas, situado muy próximo al lugar que se ha identificado como el escenario en el que tuvo lugar la famosa batalla de Munda que el día 17 de marzo del año 45 a.C. decidió a favor de César la guerra contra los hijos de Pompeyo Magno, Gneo y Sexto ${ }^{12}$. Si tal cosa es efectivamente cierta, no hay duda de que constituye un dato de gran interés que aportar al ya largo debate sobre la ubicación de Munda y del campus Mundensis, un debate que actualmente parece abandonar definitivamente la tesis que quería identificar Munda con la actual Montilla, y que lleva más bien la batalla a las proximidades de Osuna, la antigua Urso ${ }^{13}$. Sin embar-

${ }^{12}$ El llamado Cerro de las Balas se encuentra en el cortijo de El Nuño, conocido también como Cerro de la Atalaya o de las Infantas (véase al respecto A. Stylow, "Entre edictum y lex. A propósito de una nueva ley municipal Flavia del término de Écija”, en J. González (ed.), Ciudades privilegiadas en el Occidente romano, Sevilla 1999, 229-230). R. Corzo Sánchez, "Munda y las vías de comunicación en el Bellum Hispaniense", Habis 4, 1973, 247-248 y 251, hablaba en 1973 de "la aparición de una buena cantidad de glandes de plomo con la inscripción CN(eus) MAG(nus) IMP(erator) en dos yacimientos próximos a Osuna, conocidos como 'Cerro de la Camorra' y 'Cerro de la Atalaya, de las Infantas o de las Balas" (247). Afirmaba continuación sobre el Cerro de las Balas que "la copiosa aparición de este tipo de proyectiles le ha valido el citado sobrenombre de 'Cerro de las Balas'. Glandes procedentes de este lugar se conservan en el Museo Arqueológico de Sevilla... Se encuentra situado en la llamada Loma del Pozo de la Camorra" (248). Y concluía identificando Munda con el denominado "Cerro de las Balas" (251).

${ }^{13}$ La bibliografía relativa a la localización exacta del lugar en el que tuvo lugar la llamada batalla de Munda es extraordinariamente abundante. Éstos son sólo algunos de los títulos recientes más significativos: Corzo Sánchez, "Munda y las vías de comunicación" (cit. n.12), 241-252; V. Durán, La batalla de Munda, Córdoba 1984; V. Durán Recio - M. Ferreiro López, "Acerca del lugar donde se dio la batalla de Munda", Habis 15, 1984, 229-235; M. Ferreiro, César en España, Tesis Doctoral, Sevilla 1986 (microfichas en Universidad Cádiz 1988); M. Ferreiro, "Munda y el Campus Mundensis", Anales de la Universidad de Cádiz, 3-4, 1986, 123-136; M. Ferreiro, "Cronología de la campaña de Munda”, en S. Ordóñez - P. Sáez (coord.), Homenaje al profesor Presedo, 1994, 435-450; B. Segura Ramos, "Munda", Faventia 25,1, 2003, 179-183. Véase ahora sobre todo las diversas contribuciones sobre el tema en el go, no podemos sino limitarnos a informar a la comunidad científica de este dato, sin que nos haya sido posible contrastar su veracidad. Del mismo modo, tampoco estamos en condiciones de afirmar con seguridad que todas las piezas aparecieran juntas o en una misma área - otro dato de especial importancia -, aunque eso es lo que parece deducirse de la magra información aportada en su momento por el vendedor. Con estos condicionantes y limitaciones, podemos abordar la interpretación de las inscripciones que presentan las glandes en cuestión.

Parece innecesario insistir sobre el hecho de que era habitual el uso de glandes fabricadas en plomo - también existían en arcilla, aunque de manera menos habitual - por parte del ejército romano ${ }^{14}$. Algunas de ellas estaban provistas de breves inscripciones, aunque tal hecho es conocido fundamentalmente durante las guerras civiles de época tardorrepublicana ${ }^{15}$. En el caso de la guerra librada entre César y los hijos de Pompeyo, su utilización es confirmada expresamente en el texto del bellum Hispaniense. En dos ocasiones es mencionado este tipo de proyectiles, al hablar precisamente de glandes inscriptae como un instrumento para transmitir de manera rápida y concisa deter-

ya citado Melchor Gil - Mellado Rodríguez - Rodríguez Neila (eds.), Julio César y Corduba (cit. n.1). En particular, J. Gómez Pantoja, "Buscando Munda desesperadamente", 89-137, ofrece un repaso detallado al debate historiográfico sobre el tema, y M. Ferreiro López, "Munda", 381-396, insiste de nuevo en ubicar Munda en el Alto de las Camorras, situado a unos 17 kilómetros de distancia de Osuna, y el campus Mundensis en los Llanos del Águila, a los pies del Alto de las Camorras. Ésta es en la actualidad la tesis que ha alcanzado un mayor consenso entre los investigadores. Hay que señalar que el Cerro de las Balas, de cuyo entorno supuestamente proceden las glandes objeto de estudio en este trabajo, está situado a unos 12 kilómetros del Alto de las Camorras, y que los Llanos del Águila se ubican entre ambas elevaciones, cerrándose la llanura hacia el noroeste por el Cerro de la Atalaya (véanse los mapas incluidos en Ferreiro, "Munda" [cit. n.13], 392-393).

${ }^{14}$ G. Fougères, s.v. "funda" y "glans", en C. Daremberg - E. Saglio (eds.), Dictionnaire des Antiquités grecques et romaines, 1896, 1363-1366 y 1608-1611; H. Liebenam, s.v. "funditores", RE VII,1, 1910, 294-296; B. M. Henry, La fronde en Italie du VIIe s.av.J.C. à l'Empire Romain, 1971; S.J. Greep, "Lead sling-shot from Windridge Farm. St. Albans, and the use of sling by the Roman army in Britain", Britannia 18, 1987, 183-200; W.B. Griffiths, "The sling and its place in the Roman imperial army", en C. Van Driel-Murray (ed.), Roman Military Equipment: the Sources of Evidence. Proceedings of the Fifth Roman Military Equipment Conference, BAR International Series 476, Oxford 1989, 255-279; Völling, "Funditores im römischen Heer" (cit. n.4), en particular sobre glandes inscriptae p. 37 .

${ }^{15} \mathrm{Cf}$. Zangemeister, Glandes plumbeae latine inscriptae (cit. n.7); C. Cerchiai, "Le glandes plumbeae della Collezione Gorga", BCAR 88, 1984, 191-211. 
minadas informaciones ${ }^{16}$. En ambos casos, las glandes fueron usadas en el contexto del asedio al que César estaba sometiendo a la ciudad de Ategua, finalmente conquistada. De acuerdo con los datos conocidos hasta el momento, parece que fue durante el sitio de Ategua - en ella se han encontrado un cierto número de proyectiles ${ }^{17}$ - cuando comenzaron a producirse glandes inscritas, por lo tanto al comienzo del año 45 , puesto que no se ha hallado ninguna en Ulia (Montemayor), ciudad asediada por Gneo Pompeyo antes de la llegada de César a Hispania ${ }^{18}$. También resulta interesante el hecho de que no se conozcan apenas hallazgos de glandes pompeyanas en otros escenarios del bellum Hispaniense correspondientes a la actual provincia de Córdoba ${ }^{19}$, y que sí se hayan hallado proyectiles abundantes en la región sevillana entre Ecija y Osuna, en torno al castillo de Alhonoz ${ }^{20}$, Cerro de la Atalaya o Cerro de las Balas ${ }^{21}$ - lugar supuesto de origen de las piezas que aquí presentamos -, Los Argamasones ${ }^{22}$, Cerro o Alto de las Camorras ${ }^{23}$ y la misma Osuna ${ }^{24}$. Es un dato relevante que abona la tesis de que es en esta zona de la provincia de Sevilla en la que hay que situar la batalla del campus Mundensis y los episodios relacionados con ella ${ }^{25}$.

\section{Proyectiles con inscripción Cn(aeus) Mag(nus) y} L(egio) XIII

Como se puede apreciar en el catálogo de las piezas, éstas presentan cuatro diferentes inscripciones: $\mathrm{Cn}$ (aeus)

${ }^{16}$ bell.Hisp., 13,3: "idemque temporis glans missa est inscripta: quo die ad oppidum capiundum accederent, se scutum esse positurum"; 18,4: “...et indicium glande scriptum misit, per quod certior fieret Caesar, quae in oppido ad defendendum compararentur".

17 Ya Adolf Schulten mencionaba el hallazgo de "plomos de honda", procedentes de Ategua y conservados en el Museo de Córdoba en su comentario al bellum Hispaniense: Fontes Hispaniae Antiquae V, Barcelona 1940, 128.

18 Stylow, "Fuentes epigráficas para la historia de la Hispania Ulterior" (cit. n.1), 257.

19 Véase sin embargo S. Perea, "Dos nuevas glandes inscriptae de la provincia de Córdoba", en Homenaje al Profesor Montenegro, Valladolid 1999, 553-560.

${ }^{20} \mathrm{CIL} \mathrm{II}^{2} / 5983 \mathrm{a}$.

$21 \mathrm{CIL} \mathrm{II}^{2} / 51123$.

${ }^{22} \mathrm{CIL} \mathrm{II} / 51014$.

${ }^{23} \mathrm{CIL} \mathrm{II}^{2} / 51123$.

${ }^{24} \mathrm{CIL} \mathrm{II} / 5$ 1102. Véase la comparación del armamento hallado en Alesia y Osuna, dos ciudades sitiadas y tomadas por César, en el artículo de S. Sievers, "Alesia und Osuna: Bemerkungen zur Normierung der spätrepublikanischen Bewaffnung und Ausrüstung", JRMES 8, 1997, 271-276, sobre glandes inscriptae en Osuna p.274.

25 Stylow, "Fuentes epigráficas para la historia de la Hispania Ulterior" (cit. n.1), 257 y 262.
Mag(nus), L(egio) XIII, A y d(一) d(一). Las dos primeras pueden explicarse conjuntamente, porque en ambos casos proceden con seguridad del ejército pompeyano, como demostrarían no sólo sus inscripciones, sino también el hecho de que, por su similar factura, todo hace indicar que fueron fabricadas en el mismo taller y con una técnica semejante. La leyenda CNMAG que aparece en trece de nuestros ejemplares se lee sin dificultad como $C n$ (aeus) Mag(nus), y remite con seguridad a Gnaeus Pompeius Magnus, es decir, el hijo mayor de Pompeyo, del mismo nombre que su padre. Sabemos que, durante su estancia en Hispania, acunó monedas en las que aparecía mencionado como Cnaeus Magnus Imperator ${ }^{26}$. Igualmente son conocidas veinticinco glandes hispanas con esa misma denominación, portando la inscripción CNMAG en uno de sus lados, e IMP en el otro ${ }^{27}$. Por otra parte, cinco piezas conocidas hasta ahora presentan en uno de sus lados la inscripción CNMAG, y finalmente en otras dos tan sólo aparecen las letras CM, que tal vez cabría interpretar con las anteriores como $C$ (naeus) $M$ (agnus) ${ }^{28}$. Todas ellas, al igual que las que nosotros presentamos, provienen de la provincia de Sevilla y del sur de la de Córdoba, en concreto de Ategua y del área comprendida entre Osuna y Écija, es decir, las zonas en las que se desarrollaron los principales episodios de la guerra civil en los años 46 y 45 a.C. ${ }^{29}$.

Por lo que respecta a las cinco glandes con la inscripción LXIII, tampoco en este caso ofrece duda alguna su lectura, que debe ser L(egio) XIII. Hasta ahora se conocían en Hispania dos proyectiles con esa misma leyenda, acompañada en el otro lado de la pieza por un signo que parece ser la letra $Q$, cuyo significado resulta de difícil interpretación ${ }^{30}$. Ambos fueron hallados en el yacimien-

${ }^{26}$ M. Crawford, Roman Republican Coinage, Cambridge 1974, 469-471. Véase en particular L. Amela Valverde, "Acuñaciones de Cneo Pompeyo hijo en Hispania", Numisma 244, 2000, 7-33; F. Chaves Tristán, "Moneda y guerra en la Hispania del Bellum Civile", en Melchor Gil - Mellado Rodríguez - Rodríguez Neila (eds.), Julio César y Corduba (cit. n.1), 207-245, esp. 226-233.

27 Díaz Ariño, Glandes inscriptae (cit. n.1), 227 y 234, anexo no 25-49.

${ }^{28}$ Díaz Ariño, Glandes inscriptae (cit. n.1), 227 y 234, anexo $n^{\circ} 50-54$ y 55-56 respectivamente. Cf. A. Caballos Rufino, El nuevo bronce de Osuna y la política colonizadora romana, Sevilla 2006, 310, n.13: " $C(-) M(-)$, también en muchos ejemplares, desarrollados como C(neus) M(aximus)".

${ }^{29}$ Existe el paralelo de una glans, conservada en el Museo de Prehistoria de Valencia, al parecer de procedencia desconocida, que presenta exactamente la misma inscripción CNMAG: H. Bonet - A.V. Ribera, "La conquista romana i el procés de romanització en el món ibèric", en H. Bonet - R. Albiach - M. Gozalbes (eds.), Romans $i$ Visigots a les terres valencianes, Valencia 2003, 84 (lámina).

${ }^{30}$ Díaz Ariño, Glandes inscriptae (cit. n.1), 234, anexo $\mathrm{n}^{\circ}$ 58-59. Cf. el no 48 de nuestro catálogo. 
to de El Gandul (Alcalá de Guadaira, Sevilla) ${ }^{31}$. En su momento fueron atribuidos cronológicamente por sus editores a la época de la guerra anibálica. Sin embargo, esa identificación debe ser rechazada ${ }^{32}$, porque parece una época demasiado temprana para un proyectil con inscripción, conocidos sólo mucho más tarde. Es más razonable pensar que las glandes en cuestión pertenecían a una de las legiones que lucharon en territorio andaluz durante la guerra civil entre cesarianos y pompeyanos.

Cuando tuvo lugar el bellum Hispaniense, durante la parte final del año 46 y los primeros meses de 45, la famosa legio XIII que había combatido fielmente en el bando cesariano durante la primera fase de la guerra civil ya no existía. La unidad había sido disuelta por César tras su victoria en Tapso en el mes de abril del año 46, y no volvió a ser reactivada hasta los años 42-41 a.C., cuando Octaviano la reclutó y pasó a denominarla legio XIII Gemina ${ }^{33}$. A cambio, sabemos con seguridad que en el bando pompeyano, en el que luchaban trece legiones de acuerdo con el relato del bellum Hispaniense ${ }^{34}$, existió una legión identificada con el número XIII, que posiblemente combatió en la batalla de Munda y que con seguridad, tras la derrota pompeyana, defendió sin éxito frente a las tropas cesarianas la ciudad de Corduba ${ }^{35}$. Las glandes con inscripción LXIII deben por consiguiente identificarse como pertenecientes a la legión decimotercera que formó parte del ejército pompeyano en la campaña de Munda.

Tomando como probable que los proyectiles inscritos con la leyenda LXIII fueran utilizados por unidades militares pertenecientes a la legión decimotercera, y teniendo en cuenta los lugares en los que dichas piezas han aparecido, pueden seguirse parcialmente los movimientos de las tropas pompeyanas en el contexto de los acontecimientos acaecidos en torno a la batalla de Munda. Es razonable asumir que la legio XIII combatió en dicha batalla, y de ello podrían ser una prueba las glandes que

${ }^{31}$ L. Villaronga, "Diez años de novedades en la numismática hispano-cartaginesa 1973-1983”, RStudiFen., 11, 1983, 62 y 72; M. García Garrido - L. Lalana, "Algunos glandes de plomo con inscripciones latinas y púnicas hallados en Hispania", Acta Numismática 21-23, 1991-93, 102

32 Véase al respecto los atinados argumentos aducidos por Díaz Ariño, Glandes inscriptae (cit. n.1), 222-223. Cf. R. Pliego, "Sobre el reclutamiento de mercenarios turdetanos: el campamento cartaginés de El Gandul (Alcalá de Guadaira, Sevi1la)", Habis 34, 2003, 39-56.

33 J. Rodríguez González, Historia de las legiones romanas, Madrid 2001, 333.

${ }^{34}$ bell.Hisp., 7,4; 30,1; 31,10. Sobre los efectivos militares pompeyanos, L. Amela Valverde, Las clientelas de Cneo Pompeyo Magno en Hispania, Barcelona 2002, 231-237.

35 bell.Hisp., 34. Cf. Rodríguez González, Historia de las legiones romanas (cit. n.33), 330. aquí presentamos si realmente proceden del lugar del enfrentamiento. Tras la batalla de Munda, las fuerzas pompeyanas parecen haberse fracturado y desperdigado a consecuencia de su derrota. El propio Gneo Pompeyo se dirigió con algunos de sus jinetes y de sus soldados de infantería hacia Carteia, donde estaba estacionada su flota ${ }^{36}$. Otras secciones de sus tropas se refugiaron en la cercana ciudad (oppidum) de Munda, o marcharon hacia Corduba, donde se encontraba todavía Sexto Pompeyo con sus soldados ${ }^{37}$. Mientras tanto, otras legiones pompeyanas prefirieron entregarse a los vencedores ${ }^{38}$. En la defensa pompeyana de Corduba, el bellum Hispaniense menciona expresamente de manera destacada a la legio $X I I I$. Se puede por consiguiente suponer que al menos una parte de la legión decimotercera pompeyana marchó tras la batalla de Munda hacia Corduba ${ }^{39}$. La otra alternativa es que el grueso de la legión decimotercera hubiera permanecido en todo momento en el interior de Corduba, sin participar en la batalla de Munda.

La ciudad de Corduba fue tomada por César después de un sangriento asedio en el que, supuestamente, murieron veinte mil personas ${ }^{40}$. Tras este episodio la legión decimotercera no vuelve a ser mencionada. Una explicación podría ser tu total aniquilación durante el sitio, aunque tal vez hubiera supervivientes ${ }^{41}$. Si así fuera, podría suponerse que una parte de la legio XIII que había defendido Corduba huyera tras la derrota, o antes de que ésta se materializara ${ }^{42}$. Tras tomar Corduba, César se dirigió inmediatamente con su ejército hacia Hispalis (Sevilla), ciudad en la que había muchos pompeyanos, pero que también acabaría por conquistar ${ }^{43}$. El yacimiento de El

\footnotetext{
36 bell.Hisp., 32; 36-37.

37 bell.Hisp., 32. Sobre la ruta que debieron de seguir respectivamente Cneo Pompeyo hacia Carteia por un lado, y por otro Valerio hacia Corduba para informar a Sexto Pompeyo de la derrota, véase P. Sillières, "Les sources litteraires et le reseau routier de 1'Hispanie meridionale à l'époque republicaine", en J. González (ed.), Estudios sobre Urso. Colonia Iulia Genetiva, Sevilla 1989, 363-364.

38 bell.Hisp., 34.

39 J.M. Roldán, "El elemento indígena en las guerras civiles en Hispania: aspectos sociales", HAnt 2, 1972, 105, supone que quienes defendieron Corduba serían los supervivientes pompeyanos de la batalla de Munda. En contra Amela Valverde, Las clientelas de Cneo Pompeyo Magno (cit. n.34), 236, quien considera que no hubo tiempo para esa retirada, puesto que César marchó inmediatamente después de su victoria en Munda hacia Corduba.

${ }^{40}$ bell.Hisp., 34.

${ }^{41}$ Del relato del bellum Hispaniense (33-34) se desprende más bien que no hubo fugitivos de la ciudad, en la que se vivió un auténtico baño de sangre durante el sitio y tras la toma de la población.

${ }^{42}$ Cass.Dio XLIII 39 afirma que Sexto Pompeyo huyó de Corduba antes de que César llegara ante la ciudad.

${ }^{43}$ bell.Hisp., 35-36.
} 
Gandul (Alcalá de Guadaira) se encuentra situado a unos doce kilómetros de distancia de Sevilla, al este de la ciudad, en una de las rutas que discurrían entre Corduba e Hispalis. Es posible, por lo tanto, que supervivientes de la legión decimotercera marcharan hacia Hispalis en un ya desesperado intento por hacerse fuertes frente a los cesarianos, y que a ellos pertenecieran las glandes halladas en El Gandul. También es posible, como alternativa, que los proyectiles pertenecieran a soldados de la decimotercera que ya después de la batalla de Munda prefirieran huir hacia Hispalis y no hacia Corduba, aunque el protagonismo atribuido a la legión en la defensa de la ciudad cordubense hace pensar más bien que la unidad se mantuvo compacta tras Munda.

Si la hipótesis aquí planteada fuera correcta, habría por lo tanto que asumir que la llamada legio XIII pompeyana, al completo o dividida en diferentes destacamentos, combatió en la batalla de Munda, defendió posteriormente Corduba y que o bien algunos de sus supervivientes intentaron todavía resistir en Hispalis, uno de los últimos feudos pompeyanos en la Hispania Ulterior, o bien que una parte de los combatientes en el campus Mundensis prefirió marchar hacia Hispalis en lugar de dirigirse a Corduba.

\section{Proyectiles con inscripción A}

Las otras dos inscripciones presentes en los proyectiles objeto de estudio en este trabajo resultan más problemáticas en su interpretación. Los nueve ejemplares con una letra $A$ inscrita en la parte izquierda del proyectil y con una forma característica, puesto que el trazo izquierdo de la $A$ adquiere una forma curvada, tienen ya paralelos en la Hispania Ulterior. Con anterioridad fueron publicadas tres glandes exactamente con la misma inscripción procedentes, dos de ellas precisamente de El Gandul, la otra de El Palmar de Troya (Sevilla) ${ }^{44}$. En un principio, cuando las piezas de El Gandul fueron publicadas, se manejó la hipótesis de que pudiera tratarse de un signo púnico, partiendo de la base de que el yacimiento en cuestión hubiera sido un campamento en uso durante la guerra anibálica, y que en él hubieran estado asentadas tropas cartaginesa ${ }^{45}$. Una vez que ha sido desechada tal hipótesis (vid supra), también debe ser olvidada la idea de que se trate de un signo púnico. Se trata sin duda de una A latina y las glandes deben ser ubicadas cronológicamente en la época de la guerra civil entre cesarianos y pompeyanos. El hecho de que los pro-

\footnotetext{
${ }^{44}$ Díaz Ariño, Glandes inscriptae (cit. n.1), 222, anexo n ${ }^{\circ}$ 80-82.

${ }^{45}$ Villaronga, "Diez años de novedades", 72 (cit. n.31); A. Casariego - G. Cores - F. Pliego, Catálogo de plomos monetiformes de la Hispania antigua, Madrid 1987, 20-21.
}

yectiles inscritos con la letra $A$ hayan aparecido junto con otros con la inscripción LXIII en El Gandul, y que en el lote que damos a conocer en este trabajo - con las debidas reservas, teniendo en cuenta su irregular procedencia - estén vinculados supuestamente con glandes con esa misma inscripción y otros con $C N M A G$, hace pensar que se trata probablemente de proyectiles pertenecientes al bando pompeyano. Esa idea es reforzada por el hecho de que la técnica de fabricación y la forma sean semejantes en los tres grupos.

Es difícil sin embargo ir más allá. Aunque de complicada interpretación para nosotros, lógicamente debía de ser fácilmente comprendido su significado para quienes manejaban los proyectiles, para los adversarios a quienes fueran dirigidos, o para unos y otros. ¿Pudiera ser la inicial de un nombre de persona? Tal circunstancia no parece probable, puesto que no hay en la prosopografía conocida del bellum Hispaniense ningún personaje relevante cuyo nombre comience con A. Por otra parte, en los casos conocidos de glandes sobre las que fueron inscritos nombres de persona, éstos aparecen, bien completos, bien con una abreviatura que no admite duda sobre su significado. No es lógico, por lo tanto, que se hubiera usado una simple $A$ para abreviar el nombre de uno de los participantes - se entiende que destacado - en el conflicto bélico.

¿Se trata de la abreviatura de una unidad militar? Aunque las noticias sobre la participación de los funditores en el campo de batalla son escasas, sabemos que eran situados habitualmente en los laterales de las tropas dispuestas para el combate, y que solían intervenir al comienzo del enfrentamiento, arrojando sus proyectiles contra las filas enemigas con el fin de romper su disposición ${ }^{46}$. Obviamente, como tales los funditores formaban unidades, a las que César, al hablar de las tropas reunidas por su rival Pompeyo, llama "funditorum cohortes" ${ }^{47}$. Por su parte, Valerio Máximo, refiriéndose a la lucha en Sicilia del cónsul Pisón contra los esclavos, en el año 133 a.C., habla de cómo degradó a un grupo de jinetes despojándoles de sus caballos y transfiriéndoles a las "alae funditorum" ${ }^{48}$. ¿Puede la $A$ en los proyectiles ser la abreviatura de la palabra ala? ¿Puede hacer referencia a una determinada unidad de funditores del ejército pompeyano? Cabe preguntarse, no obstante, cuál sería en ese caso el sentido o la necesidad de la individualización de esas glandes. No queda otro remedio que concluir que el significado de la $A$ sobre los proyectiles sigue siendo oscuro.

\footnotetext{
${ }^{46}$ Veget., mil., I 20; II 17; Caes., civ., III 46,2.

${ }^{47}$ Caes., civ., III 4.

${ }^{48}$ Val.Max., II 7,9: "L. Calpurnius Piso cónsul... turmasque equitum, quibus praefuerat, ademptis equis in funditorum alas transscripsit".
} 


\section{Proyectiles con inscripción $d(-) d(-)$}

Hasta la fecha, que sepamos, no se había publicado ningún proyectil con la leyenda $d(-) d(-)$, de los que aquí presentamos diecinueve ejemplares. Como en el caso anterior, hay que partir de la idea de que la inscripción debía ser de fácil comprensión para emisarios y receptores de las glandes. Se puede suponer razonablemente que se trataría de una abreviatura, el problema es establecer a que palabras o expresión correspondería. Las inscripciones conocidas sobre glandes, al margen de algunos signos de difícil interpretación, se refieren habitualmente a nombres de personas o a unidades militares ${ }^{49}$. En este caso, $d(-) d(-)$ no parece identificable con ninguna unidad militar, ni tampoco con ninguno de los individuos presentes en el conflicto que nos son conocidos a través de las fuentes antiguas ${ }^{50}$. También se conocen proyectiles que contienen expresiones que pueden ser, bien propiciatorias en honor de una divinidad ${ }^{51}$, bien frases o palabras contra los enemigos para que las glandes les causen daño ${ }^{52}$. En este apartado cabría incluir las piezas con la inscripción $a c(c)$ ipe, que podría traducirse como "toma eso" o "ahí va eso" "53. ¿Habría que entender los proyectiles con la leyenda $d(-) d(-)$ en ese sentido, como expresión propiciatoria o denigratoria? Partiendo de esta hipótesis, sería posible por ejemplo interpretar $d(-) d(-)$ como la abreviatura de $d$ (ono) $d$ (atum), algo así como "toma este regalo", o $d$ (amnum) $d($ et $)$, "que haga daño", y existirían sin duda otras posibilidades.

Hay sin embargo razones para cuestionar esta hipótesis. Por una parte, habría que preguntarse hasta qué punto esa abreviatura sería inmediatamente interpretada de manera correcta. A ese respecto, la palabra "accipe" antes mencionada se inscribe completa para que no haya duda sobre lo que se desea transmitir. Y son conocidos

${ }^{49}$ En Hispania se conocen proyectiles con los nombres Quintus Metellus, Quintus Sertorius y el ya citado Gnaeus Pompeius, así como otros con Leg(io) II, además de los mencionados con L(egio) XIII. Cf. Díaz Ariño, Glandes inscriptae (cit. n.1), anexo pp.233-235.

50 Véase la prosopografía del conflicto conocida a través del bellum Hispaniense en C. González Román - Mª A. Marín Díaz, "El Bellum Hispaniense y la romanización del sur de la Península", Hispania Antiqua 11-12, 1981-85, 28-34; C. González Román, "Prosopografía del Bellum Hispaniense", en Melchor - Mellado - Rodríguez-Neila (eds.), Julio César y Corduba (cit. n.1), 281-309.

51 Véase por ejemplo en Hispania la expresión Iovis vict(oria). Cf. Díaz Ariño, Glandes inscriptae (cit. n.1), anexo nº 83-85.

${ }^{52} \mathrm{Cf}$. Zangemeister, Glandes plumbae latine inscriptae (cit. n.7), no 9-13, 27-31, 34 (todos procedentes de Asculum), 56, 58, 61-62, 64-67, 84, 89 (de Perusia).

${ }^{53}$ En Hispania se conocen varios ejemplares con esa leyenda, así como uno con la inscripción Cae(sar?) ac(c)ipe. Cf. Díaz Ariño, Glandes inscriptae (cit. n.1), anexo n 61-65. sobre glandes incluso mensajes relativamente largos y complejos, en los que los emisarios se han molestado en escribir sobre los proyectiles frases enteras. Para que tuviera el efecto deseado, $d(-) d(-)$ debería ser una abreviatura de fácil trascripción en el contexto de un enfrentamiento militar, algo que, por la falta de paralelos, no está en absoluto claro.

Hay otra razón que hace dudar de que ésa sea la interpretación correcta, cual es la forma de realizar la inscripción sobre las glandes. A diferencia de todas las demás glandes que aquí se presentan - y de la gran mayoría de las conocidas en general -, en las que las inscripciones han sido realizadas con molde en el momento de fabricar los proyectiles y aparecen resaltadas en relieve sobre su superficie, las leyendas $d(-)$ $d(-)$ fueron realizadas mediante la impresión de un sello sobre los proyectiles una vez que éstos habían sido fabricados. La existencia de un sello sugiere algún tipo de ámbito oficial, quizás una autoridad que hubiera ordenado marcar las glandes con esa leyenda. Y si pensamos en una inscripción con un significado oficial, la hipótesis nos remite inmediatamente a la posibilidad de que la abreviatura $d(-) d(-)$ pueda leerse como $d($ ecreto) d(ecurionum), una fórmula muy habitual en el ámbito municipal de las provincias romanas, entre ellas desde luego Hispania, aunque ciertamente no existen paralelos en glandes para esta inscripción ${ }^{54}$. Esta posible interpretación no está, sin embargo, exenta de difi-

\footnotetext{
${ }^{54}$ Varias series de monedas acuñadas en Carteia entre el período triunviral y el augústeo (40 a.C.-15 d.C.) portan primero la leyenda EX DD (series 24, 25 y 26A), luego sólo DD (series 26B, 27, 28 y 29) ( $\mathrm{M}^{\mathrm{a}}$ P. García-Bellido - C. Blázquez, Diccionario de cecas y pueblos hispánicos con una introducción a la numismática antigua de la Península Ibérica, vol.2, Madrid 2002, 93-94). En las monedas acuñadas durante las épocas de Augusto y Tiberio en diversas ciudades de Hispania (y en otros lugares del Imperio romano, como Nemausus, pero también en Oriente), existen contramarcas con el sello DD, sin ninguna duda con el significado de d(ecreto) d(ecurionum) e impresas con el propósito de confirmar o revalidar el valor de las monedas. Es el caso de Emporiae (A. Guadán, "Tipología de las contramarcas en la numismática ibero-romana", Numario Hispánico IX, 17, Madrid 1960, 6469; A. Burnett, M. Amandry, P.P. Ripollès, Roman Provincial Coinage, I,1, Londres-París 1992, 105-109, n 241, 254 y 257); Ebora (Guadán 62; RPC I,1, 74 n51); Iulia Traducta ( $R P C \mathrm{I}, 1$, 83-84, nº7-108); Saguntum (Guadán 92; RPC I,1, 100, no202); Tarraco (Guadán 97; RPC I,1, 105, nº228); Celsa (Guadán 46-47; $R P C \mathrm{I}, 1,113, \mathrm{n}^{\circ} 278$ ); y Calagurris (Guadán 25-26; RPC I,1, 136-137; $\mathrm{n}^{\circ} 435$ y 439). Véase asimismo sobre las contramarcas en Hispania, García-Bellido - Blázquez, Diccionario de cecas y pueblos hispánicos, vol.1, 109-114, en particular sobre d(ecreto) d(ecurionum) p.114. Contramarcas augústeas con el sello DD en Novaesium: H. Chantraine, Novaesium VIII. Die Antiken Fundmünzen von Neuss. Gesamtkatalog der Ausgrabungen 1955-1978, Berlín 1982, 36.
} 
cultades. La fórmula decreto decurionum es muy frecuente en Hispania a partir de la época augústea, pero no en época republicana, si bien hay que tener en cuenta a ese respecto, tanto la mayor escasez de epigrafía latina en ese período, como la escasa implantación de coloniae y municipia - el primer municipium sería Gades - en Hispania en época precesariana, y en consecuencia la ausencia de una organización local en la que tuviera cabida un ordo decurionum. Por otra parte, ¿por qué razón se habría hecho inscribir sobre glandes la inscripción "decreto decurionum”? ¿Cuál sería la intervención de los decuriones de una determinada ciudad en el conflicto bélico como para ordenar o para certificar con su firma la fabricación de glandes?

En la guerra librada en la Hispania Ulterior en los años 46-45 a.C. entre César y los hijos de Pompeyo desempeñaron un papel fundamental las ciudades ${ }^{55}$. En el relato que se hace en el bellum Hispaniense de los diversos acontecimientos, la cuestión clave es en todo momento el control de las ciudades más importantes del valle del Guadalquivir ${ }^{56}$. De hecho, cuando César llegó con sus tropas a Hispania, la mayoría de esas ciudades apoyaban a los pompeyanos, con la excepción de Ulia, al sur de Corduba, que estaba entonces siendo sitiada por Gneo Pompeyo ${ }^{57}$, de Gades, donde estaba la flota cesariana y que mantenía una estrecha relación con César, personificada en la familia de los Balbos ${ }^{58}$, y de Carruca ${ }^{59}$. La población más importante de la provincia, Corduba, estaba en poder de los pompeyanos, y en ella estaba acantonada una guarnición al mando de Sexto Pompeyo ${ }^{60}$. También estaban bajo el control

\footnotetext{
${ }^{55}$ Sobre la situación jurídica de las ciudades andaluzas en época republicana, véase $\mathrm{M}^{\mathrm{a}} \mathrm{A}$. Marín Díaz, Emigración, colonización y municipalización en la Hispania republicana, Granada 1988; C. González Román, "Las colonias romanas de la Hispania meridional en sus aspectos socio-jurídicos", en C. González Román (ed.), La Bética en su problemática histórica, Granada 1991, 87-110; J. González, "Colonización y municipalización cesariana en la Ulterior", en Melchor - Mellado Rodríguez Neila (eds.), Julio César y Corduba (cit. n.1), $397-$ 412. Cf. asimismo González Román - Marín Díaz, "El Bellum Hispaniense" (cit. n.50), 18-28.

56 Para los acontecimientos previos a la decisiva batalla de Munda, véase L. Amela Valverde, "Cneo Pompeyo hijo en Hispania antes de la batalla de Munda", Espacio, tiempo y forma. Serie II. Historia Antigua 13, 2000, 357-390; E. Melchor Gil, "Entre Corduba y Munda: la campaña militar del 45 a.C .y su desarrollo en la campiña de Córdoba", en Melchor - Mellado Rodríguez-Neila (eds.), Julio César y Corduba (cit. n.1), 361-379.

${ }^{57}$ bell.Hisp., 4. Por su fidelidad, Ulia recibió después el sobrenombre de Fidentia.

${ }^{58}$ bell.Hisp., 37 y 40.

${ }^{59}$ bell.Hisp., 27,5.

${ }^{60}$ bell.Hisp., 3.
}

pompeyano Ategua, largamente sitiada por César ${ }^{61}$, Ucubis, donde también había una guarnición ${ }^{62}$, Urso ${ }^{63}$, Carteia, donde se refugiaba la flota pompeyana ${ }^{64}$, Hispalis ${ }^{65}$, Munda, finalmente tomada por Fabio Máximo tras la batalla del campus Mundensis ${ }^{66}$, Bursavo, cuyo habitantes participaron en la defensa de Ategua ${ }^{67}$, y previsiblemente también poblaciones de menor entidad como Soricaria, Aspavia, Ventipo, Hasta, asimismo mencionadas en el bellum Hispaniense ${ }^{68}$. Cuando César, tras vencer en la batalla del campus Mundensis, hubo conquistado Corduba, Munda, Urso e Hispalis ${ }^{69}$, pronunció en esta última ciudad un discurso en una contio abierta a todos los habitantes de la población para recriminar a los hispanos haber tomado el bando pompeyano frente a él y contra Roma ${ }^{70}$, lo cual sirve para resaltar la generalidad del apoyo de las ciudades de la Hispania Ulterior a los hijos de Pompeyo Magno.

En una guerra civil, no siempre es posible determinar con seguridad si la toma de partido por uno de los dos bandos contendientes se debía al convencimiento o a la imposición. Tal vez la presencia en la Hispania Ulterior de los pompeyanos con un buen número de tropas - hasta trece legiones, aunque su formación y su número debían de ser irregulares dadas las circunstancias excepcionales ${ }^{71}$ - pudo forzar a algunas ciudades a posicionarse a favor de los hermanos Pompeyo, prefiriendo esta opción a la de enfrentarse a ellos. Sin embargo, la tenacidad con la que algunas de las ciudades bajo control pompeyano resistieron los asedios de César sin entregarse, tanto antes como después de la batalla de Munda, hace sospechar que la adscripción al bando pompeyano fue en buena medida resultado de la

\footnotetext{
${ }^{61}$ bell.Hisp., 6ss.

${ }^{62}$ bell.Hisp., 27.

${ }^{63}$ bell.Hisp., 28.

${ }^{64}$ bell.Hisp., 32.

${ }^{65}$ bell.Hisp., 35.

${ }^{66}$ bell.Hisp., 41.

${ }^{67}$ bell.Hisp., 22.

${ }^{68}$ bell.Hisp., 22; 24; 27. Cf. González Román - Marín Díaz, "El Bellum Hispaniense" (cit. n.50), 20-25.

${ }^{69}$ Cass.Dio XLIII 39.

${ }^{70}$ bell.Hisp., 42. El apoyo de las ciudades del sur de Hispania a la causa pompeyana es asimismo enfatizado por Casio Dión (XLIII 31).

71 Ésta es la descripción que se hace en el bellum Hispaniense de las legiones pompeyanas en la campaña de Munda: "Aquilas et signa habuit XIII legionum; sed ex quibus aliquid firmamenti se existimabat habere duae fuerunt, Vernacula et Secunda, quae a Trebonio transfugerant, una facta ex colonis qui fuerunt in his regionibus, quarta fuit Afraniana ex Africa, quam secum adduxerat; reliquiae ex fugitivis auxiliaribusque consistebant" (bell.Hisp., 7,4-5).
} 
convicción y no sólo de la obligación. Debió de existir en el seno de las ciudades hispanas un debate, en particular entre las elites locales, sobre la conveniencia o no de participar en el conflicto y de apoyar a uno $\mathrm{u}$ otro bando. En el relato del bellum Hispaniense hay algunos indicios de ese debate interno, como en el intento de los habitantes de Ategua por llegar a un acuerdo con César ${ }^{72}$, en la división existente en Ucubis entre los partidarios de Pompeyo y los de César ${ }^{73}$, en la discusión entre los ciudadanos de Carteia sobre qué hacer con Gneo Pompeyo, si entregarlo o no a César para ganarse su clemencia ${ }^{74}$, y desde luego en Corduba, donde la presencia de ciudadanos romanos agrupados en un conventus desempeñó sin duda un papel relevante ${ }^{75}$. Se puede por lo tanto suponer que fueran los órganos políticos internos de los que estuvieran dotados las diferentes comunidades urbanas hispanas, los que tomaran en su momento la difícil decisión de apoyar a César, a los pompeyanos o de intentar permanecer neutrales.

$\mathrm{Y}$ es en ese contexto excepcional de una guerra civil, que era además en buena medida un conflicto de legitimidades, en el que tendría sentido la inscripción d(ecreto) d(ecurionum) sobre proyectiles destinados a ser utilizados en la contienda. Obviamente, la existencia de decuriones en una ciudad implicaría necesariamente una organización municipal o colonial. La lex Ursonensis por la que había de regirse la Colonia Genetiva Iulia Urbanorum Urso, en la que el ordo decurionum constituía el elemento central a imagen y semejanza del senado de Roma, es inmediatamente posterior a la finalización de la guerra civil ${ }^{76}$. Fue en ese momento cuando, por iniciativa del dictador César, diferentes ciudades hispanas fueron promocionadas al estatuto de colonias o municipios. Hasta entonces, eran muy pocas las ciudades privilegiadas que, por consiguiente, debían de con-

\footnotetext{
72 bell.Hisp., 13.

${ }^{73}$ bell.Hisp., 20,1-3; 21,3.

${ }^{74}$ bell.Hisp., 37.

${ }^{75}$ La presencia en Corduba de filopompeyanos y filocesarianos a lo largo de todo el conflicto es recogida en las fuentes antiguas (bell.Hisp., 2), y se convirtió en confrontación abierta dentro de la ciudad cuando ésta fue sitiada por César tras la batalla de Munda (bell.Hisp., 34,1). Al respecto, J.F. Rodríguez Neila, "Corduba entre cesarianos y pompeyanos durante la guerra civil", en Melchor Gil - Mellado Rodríguez - Rodríguez Neila (eds.), Julio César y Corduba (cit. n.1), 320-325 y 344-345; Caballos Rufino, El nuevo bronce de Osuna (cit. n28), 322.

${ }^{76}$ Véase ahora Caballos Rufino, El nuevo bronce de Osuna (cit. n28), passim. Del mismo autor, "La actividad colonizadora en la Provincia Hispania Ulterior a fines de la República: la nueva tabla inédita de la ley de Osuna y el deductor coloniae", en Melchor Gil - Mellado Rodríguez - Rodríguez Neila (eds.),
} Julio César y Corduba (cit. n.1), 413-428. tar en su seno con decuriones, y que, por lo tanto, pudieron haber inscrito la leyenda decreto decurionum sobre los proyectiles en cuestión. Lógicamente, hay que centrar esa posibilidad entre las ciudades que se involucraron activamente en la guerra. Gades era posiblemente un municipium desde el año 49 por concesión de César ${ }^{77}$. Su papel en la guerra civil fue relevante, en tanto que refugio de la flota cesariana, pero no participó directamente en los combates, por lo que habría que descartarla. Por otra parte, el hecho de que, hasta ahora, sólo se conozcan glandes con inscripción pertenecientes al bando pompeyano inclina a pensar en una población que tomara partido por los hermanos Pompeyo. En ese sentido, Carteia, que era colonia latina desde el año 171 a.C. ${ }^{78}$, podría ser una candidata. Sin embargo, como en el caso de Gades, Carteia no parece haber participado directamente en combates, y se limitó a ser el lugar de refugio de la flota pompeyana.

Quedan otras dos posibilidades, Munda y Corduba. En ambos casos, su estatuto jurídico en el año 45 es controvertido. Por lo que respecta a Corduba, de ella se ha discutido y se discute, tanto la fecha concreta de su fundación, en cualquier caso llevada a cabo por M. Claudio Marcelo en el siglo II a.C. ${ }^{79}$, como su estatuto jurídico y la composición de su población. Plinio la llama Colonia Patricia Corduba ${ }^{80}$, pero la cuestión es saber desde cuando ostentó la ciudad el status de colonia. Básicamente, las opiniones se dividen entre quienes consideran que en el momento de su fundación no recibió ningún status privilegiado, sino que permaneció como una ciudad peregrina hasta la época de la guerra civil entre cesarianos y pompeyanos, o hasta la época

\footnotetext{
77 Ésa es la opinión mayoritaria entre los investigadores. Véase por ejemplo J.F. Rodríguez-Neila, El municipio romano de Gades, Cádiz 1980, 50ss.; Marín Díaz, Emigración, colonización y municipalización (cit. n.55), 214-215. Sin embargo, recientemente González, "Colonización y municipalización cesariana en la Ulterior" (cit. n.55), 410-411, lo ha puesto en duda, considerando más probable que Gades fuera una colonia latina cesariana, transformada en municipio por Augusto. El mismo autor opina (410) que la ciudad de Italica debió de alcanzar el estatuto de municipium con anterioridad a la guerra civil o con César. Si así fuera, Italica podría entrar hipotéticamente en el grupo de ciudades provistas de decuriones en el año 45 , pero es en cualquier caso descartable en nuestro análisis dado que no tuvo una intervención directa en el conflicto bélico.

${ }^{78}$ Liv., XLIII 3,1ss.

79 Str., III 2,1. Sobre los restos arqueológicos de Corduba en su período fundacional, véase J.F. Murillo - J.L. Jiménez, "Nuevas evidencias sobre la fundación de Corduba y su primera imagen urbana", en J.L. Jiménez - A. Ribera (coord.), Valencia y las primeras ciudades romanas de Hispania, Valencia 2002, 183-193.

${ }^{80}$ Plin., n.h., III 10.
} 
augústea $^{81}$, y quienes piensan por el contrario que era una colonia latina ya desde el siglo II $^{82}$. Se aduce a favor de esta tesis la mención de unas "cohortes colonicae" de César, que habrían sido reclutadas supuestamente en Corduba $^{83}$. La creación de una colonia romana en una provincia en la primera mitad del siglo II a.C. resulta excesivamente temprana, mientras que ya existía en Hispania el precedente de Carteia como colonia latina antes de que Corduba fuera fundada ${ }^{84}$ (más tarde sería fundada Valentia también como colonia latina). Además, la mención de la existencia en los años 48 y 47 a.C. de conventus civium romanorum en Corduba ${ }^{85}$ sería incompatible con su hipotético estatuto de colonia romana, pero no con el de colonia latina ${ }^{86}$. Se ha apun-

${ }^{81}$ Entre otros, J.F. Rodríguez Neila, "Introducción a la "Corduba' romana en época republicana", en AAVV, Córdoba. Apuntes para su historia, Córdoba 1981, 107-134, esp.122; Marín Díaz, Emigración, colonización y municipalización (cit. n.55), 132-133; 205-207; MªA. Marín Díaz, "Problemas históricos en torno a las fundaciones romanas de la Hispania meridional durante el siglo II a. de C.", en González Román (ed.), La Bética en su problemática histórica (cit. n.55), 148-151.

${ }^{82}$ H. Galsterer, Untersuchungen zum römischen Städtewesen auf der iberischen Halbinsel, Berlín 1971, 9-10 y 66, considera que Corduba fue colonia latina desde su fundación, promocionada por Augusto a colonia romana, y que entonces habría pasado a denominarse Patricia, un cognomen que no podía proceder del plebeyo Marcelo. En el mismo sentido, otros investigadores han defendido asimismo la condición de colonia latina de Corduba desde el momento de su creación: P. Le Roux, L'armée romaine et l'organisation des provinces iberiques d'Auguste à l'invasion de 409, París 1982, 35-36; R. Knapp, Roman Córdoba, Berkeley - Los Angeles - Londres, 1983, 11; A. Canto, "Colonia Patricia Corduba: nuevas hipótesis sobre su fundación y nombre", Latomus 50, 1991, 846-857; A. Stylow, "De Corduba a Colonia Patricia. La fundación de la Corduba romana", en P. León (ed.), Colonia Patricia Corduba. Una reflexión arqueológica, Córdoba 1996, 77-78; A. Canto, "Algo más sobre Marcelo y las colonias romanas del año 45 a.C.", Gerión 15, 1997, 253-281, esp.263 y 274.

${ }^{83}$ Caes., civ., II 19,3. Al respecto Rodríguez Neila, "Corduba entre cesarianos y pompeyanos" (cit. n.75), 330: "Quizás tales cohortes habían sido reclutadas, al menos parcialmente, en la misma Corduba y entre sus habitantes romanos, pues su rápida disposición a defenderla sólo se explica si tenían vínculos especiales con la ciudad". En contra, A.J.N. Wilson, Emigration from Italy in the Republican Age of Rome, Manchester 1966, 16 n.8; Amela Valverde, Las clientelas de Cneo Pompeyo Magno (cit. n.34), 234. Cf. Marín Díaz, Emigración, colonización y municipalización (cit. n.55), 175-176.

${ }^{84}$ Salvo que se acepte la tesis defendida por Alicia Canto, quien ha argumentado (véase sus trabajos en nota 82) en el sentido de que Corduba debió de ser fundada como colonia latina ya en torno al año 200 a.C.

${ }^{85}$ Caes., civ., II 19,3; II 21,1.

${ }^{86}$ Cf. Rodríguez Neila, "Corduba entre cesarianos y pompeyanos" (cit. n.75), 311-312. tado asimismo la posibilidad de que fueran los hijos de Pompeyo Magno quienes concedieran a Corduba el estatuto de colonia, lo cual explicaría la fidelidad a su causa $^{87}$. César habría respetado posteriormente ese estatuto dentro de su política de clementia con los vencidos. Recientemente Julián González, sobre la base de la adscripción de los cordubenses a la tribu Sergia, considera que Corduba debió de ser una colonia, bien ya antes de César, o bien fruto de una deductio llevada a cabo por el mismo César, existiendo con posterioridad otro asentamiento que explicaría la presencia de la tribu Galeria ${ }^{88}$ En cualquier caso, aunque no exista un argumento absolutamente definitivo al respecto y el debate sigue vivo, resulta plausible que Corduba fuera colonia latina antes del año 45.

Corduba, la ciudad más importante de la Hispania Ulterior, constituía el cuartel general de los pompeyanos, que la consideraban la capital de la provincia ${ }^{89}$, y en ella residía Sexto Pompeyo con un destacamento. La información proporcionada en el bellum Hispaniense, en el sentido de que una de las legiones de los pompeyanos - diferente de la Vernacula - había sido reclutada "ex colonis qui fuerunt in his regionibus", podría aludir a soldados reclutados en Corduba ${ }^{90}$. ¿Sería esa legión formada por colonos la legio XIII que defendió Corduba del asedio cesariano? ¿Explicaría precisamente su origen cordubense su fiel resistencia en la ciudad ante César? La posesión de la que era, de iure o de facto, la capital de Hispania Ulterior, debía de significar para los pompeyanos una manera de resaltar la legitimidad de su

${ }^{87}$ González Román - Marín Díaz, "El Bellum Hispaniense" (cit. n.50), 21.

${ }^{88}$ González, "Colonización y municipalización cesariana en la Ulterior" (cit. n.55), 406.

${ }^{89}$ bell.Hisp., 3: "quod eius provinciae caput esse existimatur". No hay seguridad de que Corduba fuera oficialmente la capital de la provincia hasta época augústea, pero, por su importancia, debió de ser regularmente la residencia del gobernador y debió de desempeñar, si no oficialmente, al menos sí oficiosamente, el papel de capital. Al respecto véase, R. Haensch, Capita provinciarum. Statthaltersitze und Provinzialverwaltung in der römischen Kaiserzeit, Mainz 1997, 178-185. Sobre la importancia de la ciudad por reunir unas inmejorables condiciones topográficas para su defensa y dominar un importante eje de comunicaciones terrestres, así como sobre el papel de Corduba en la guerra civil, véase Rodríguez Neila, "Corduba entre cesarianos y pompeyanos" (cit. n.75), 312-317 y 327-355. Cf. S. Panzram, Stadtbild und Elite: Tarraco, Corduba und Augusta Emerita zwischen Republik und Spätantike, Stuttgart 2002, 129-225.

${ }^{90}$ Véase sin embargo A.T. Fear, "The Vernacular Legion of Hispania Ulterior”, Latomus 50, 1991, 820, quien es escéptico sobre el número de ciudadanos romanos de procedencia hispana que combatieran en las filas pompeyanas. 
lucha contra César ${ }^{91}$. Por esa razón, Corduba fue desde el comienzo de la campaña en Hispania el principal objetivo de César. Su primera intención al llegar al valle del Guadalquivir fue tomar la ciudad. La defensa de Sexto y la ayuda prestada por Gneo lo impidieron ${ }^{92}$. El asedio de Ategua y otros episodios condujeron a los contendientes a la batalla de Munda, pero, en el momento en que se vio vencedor, César se dirigió inmediatamente a Corduba. La conquista de la ciudad, defendida fundamentalmente por la legión decimotercera pompeyana y otros supervivientes del campus Mundensis, terminó de decidir la campaña a favor de César ${ }^{93}$.

En el contexto de la centralidad que en el terreno militar, pero también político, tuvo Corduba durante el bellum Hispaniense, ¿resulta plausible que los decuriones de la colonia decidieran colocar o autorizaran la colocación de la leyenda d(ecreto) d(ecurionum) sobre glandes? Y en ese caso, ¿por qué? Proyectiles de honda, con o sin inscripción, serían sin duda fabricados y almacenados en Corduba para la defensa de la ciudad por parte de las tropas pompeyanas acantonadas en ella. Gneo y Sexto Pompeyo pudieron estar interesados en señalar en una serie de proyectiles que contaban con el apoyo expreso del ordo decurionum cordubense, no tanto para indicar este hecho a los adversarios como para resaltarlo como elemento de legitimación entre sus propios soldados. Aunque las glandes en cuestión estuvieran primariamente destinadas a la defensa de Corduba, pudieron ser utilizadas lógicamente por las tropas pompeyanas en otros escenarios, en particular en la batalla de Munda de la que supuestamente proceden. Ahora bien, mientras en Corduba una leyenda decreto decurionum sin mayores especificaciones podía ser fácilmente entendida, cabe preguntarse hasta qué punto seguiría siendo comprendida en un campo de batalla situado a una cierta distancia de la ciudad, al no ir acompañada de referencia

${ }^{91} \mathrm{Si}$ es correcta la interpretación de R. Vollkommer, "Darstellungen der Personifikation von Tarragona", en $L a$ ciudad en el mundo romano. Actas del XIV Congreso Internacional de Arqueología Clásica. Vol.2. Comunicaciones, Tarragona 1994, 436-438, un denario atribuido a la ceca de Corduba y emitido en 46-45 a.C. por Gneo Pompeyo representaría a las ciudades de Tarraco y Corduba, personificadas por dos diosas tocadas con coronas en forma de sendas torres, mostrando implícitamente su apoyo al bando pompeyano. Obviamente se trataría de enfatizar la toma de posición de importantes ciudades hispanas a favor de los pompeyanos mediante la iconografía numismática. Cf. D.R. Sear, The History and Coinage of the Roman Imperators 49-27 BC, Londres 1998, 35-37, no49-52; Caballos Rufino, El nuevo bronce de Osuna (cit. n.76), 308, n.2.

${ }^{92}$ bell.Hisp., 2-4; Cass.Dio XLIII 32.

${ }^{93}$ bell.Hisp., 33-34. alguna a la población de procedencia, a no ser que no cupiera duda alguna sobre a qué decuriones debía referirse la inscripción. En cualquier caso, es también cierto que, independientemente de sus mensajes o identificaciones, las glandes eran ante todo instrumentos de guerra y como tal habían de ser utilizadas.

En cuanto a Munda, de un pasaje de Plinio parece deducirse que había sido colonia inmunis, para añadir a continuación el autor latino que la ciudad había sido destruida cuando Gneo Pompeyo fue derrotado ${ }^{94}$. El problema a la hora de interpretar el texto pliniano es que no existe plena seguridad sobre la ubicación precisa de la ciudad de Munda y, por lo tanto, no ha sido posible hasta el momento determinar a través de los restos arqueológicos si la población dejó de existir tras ser tomada por las tropas cesarianas en el año 45, como parece deducirse del pasaje en cuestión ${ }^{95}$, o si siguió estando habitada con posterioridad a la guerra civil. En el primero de los casos, Munda sólo pudo haber disfrutado del estatuto de colonia antes del año 45 - ¿por iniciativa de los pompeyanos? -, y por lo tanto lo sería en el momento en que tuvo lugar la batalla en el campus Mundensis ${ }^{96}$. En la segunda de las hipótesis, Munda se habría convertido en colonia tras la victoria cesariana, en el contexto de la política de clemencia del dictador.

Está claro que, si se admitiera que Munda era una colonia en los primeros meses del año 45 , las glandes con $d(-) d(-)$ hubieran podido provenir de ella, puesto que la batalla decisiva - en cuyo entorno han aparecido supuestamente los proyectiles - se desarrolló junto a la ciudad. De hecho, del relato que de la batalla hace el bellum Hispaniense se deduce con claridad que Gneo Pompeyo había colocado sus tropas en un lugar elevado al abrigo de las murallas de Munda: "Etenim et natura loci defendebantur et ipsius oppidi munitione ubi castra habuit constituta" ${ }^{97}$. Los pompeyanos se encontraban por consiguiente junto a la ciudad y protegidos por ella, y entre su campamento y el de los cesarianos se extendía una llanu-

94 Plin., n.h., III 12: "Huius conventus sunt reliquae coloniae inmunes Tucci quae cognominatur Augusta Gemella, Ituci quae Virtus Iulia, Ucubi quae Claritas Iulia, Urso quae Genetiva Urbanorum, inter quae fuit Munda, cum Pompeio filio rapta".

95 Canto, "Algo más sobre Marcelo..." (cit. n.82), 277: "La hasta entonces colonia pompeyana de Munda, perdidos ciudad, tierras y estatuto, literalmente fue barrida por César de la Historia".

${ }^{96}$ Ésa es la opinión de Galsterer, Untersuchungen (cit. n.82), 14. Recientemente se ha propuesto que Gneo Pompeyo Magno habría convertido en colonia a Cartago Nova en torno al año 54 a.C.: J.M. Abascal, "La fecha de la promoción colonial de Carthago Nova y sus repercusiones edilicias", Mastia 1 (2002) 21-44.

97 bell.Hisp., 28,3. 
ra de unas cinco millas de longitud ${ }^{98}$. Cuando los soldados de César avanzaron para entablar el combate, los pompeyanos no se atrevieron en un principio a abandonar la protección de las murallas de la ciudad ${ }^{99}$. Finalmente, los pompeyanos presentaron combate, con el resultado conocido, la gran victoria de los cesarianos. Miles de hombres murieron, y de entre los partidarios de Pompeyo se salvaron sobre todo aquéllos que se refugiaron en Munda: “...evaserunt] ex fuga hac qui oppidum Mundam sibi constituissent praesidium" ${ }^{100}$. Teniendo en cuenta, por lo tanto, la estrecha implicación de Munda en la batalla librada frente a sus muros el día 17 de marzo del año 45 a.C., es evidente que una leyenda $d$ (ecreto) d(ecurionum), aun sin especificar el nombre de la ciudad en cuestión, habría sido fácil de entender como procedente de la colonia próxima al escenario de la batalla. A la inversa, la existencia de proyectiles con esa leyenda procedentes de Munda probaría indirectamente la condición de colonia de la ciudad, tal y como se deduce del texto de Plinio.

Hay una última y decisiva cuestión que hay que plantearse en este contexto: ¿tenían los decuriones de una colonia la potestad de intervenir de alguna manera en la defensa de su ciudad? A ese respecto, es preciso remitirse a la antes mencionada lex Ursonensis, que entró en vigor con la creación de la colonia Urso poco después de que se produjeran los hechos narrados en el bellum Hispaniense, apenas dos años más tarde de que, de acuerdo con la hipótesis que aquí manejamos, las glandes con la inscripción $d(-) d(-)$ fueran fabricadas. En el capítulo 103 de dicha ley, se afirma que es el duovir o, en su lugar, el praefectus, el encargado de reclutar en caso de necesidad a coloni, incolae y contributi para la defensa de la ciudad, en concreto hasta los límites de la colonia ("coloniae finium defendendorum causa"). Pero la ley especifica expresamente que, para llevar a cabo tal movilización y armar a los habitantes de la colonia, era imprescindible contar previamente con la autorización de la mayoría de los decuriones - aparentemente sin que fuera necesario un quórum de votación: "maior pars qui tum aderunt" -,

98 bell.Hisp., 29,1: "Planities inter utraque castra intercedebat circiter milia passuum V, ut auxilia Pompei duabus defenderentur rebus, oppido et excelsi loci natura". Cf. V. Durán Recio, "Muerte de Attius Varus en Munda", en González (ed.), Estudios sobre Urso (cit. n.37), 367-374, quien identifica la ciudad de Munda con los restos existentes en el Cerro de las Camorras, "una colina tabular de forma oval", delante de cuyas murallas en su parte oriental habría situado su campamento Pompeyo. Frente al Cerro de las Camorras y dominada por la colina se extiende una amplia llanura, conocida como los Llanos del Águila, con una extensión de aproximadamente cinco millas, como el bellum Hispaniense afirma.

99 bell.Hisp., 29,6: "Qui tamen a munitione oppidi longius non audebant procedere, in quo sibi prope murum adversarii constituebant". La idea se repite en 29,7.

${ }^{100}$ bell.Hisp., 32,1. sin duda a través de un decreto emitido por el ordo decurionum (en el texto epigráfico se utilizan los verbos decernere y censire ${ }^{101}$. Es discutible si se trataba de una cláusula específica para la colonia de Urso, o si fue extraída de alguna de las colonias fundadas en la Península Itálica en los siglos anteriores ${ }^{102}$. En cualquier caso, estando en el momento de la fundación de la colonia de Urso tan reciente la guerra entre cesarianos y pompeyanos, y en pleno desarrollo de la confrontación bélica que siguió al asesinato de César, parece justificada la referencia en la lex coloniae a la eventualidad de armar a los habitantes de la ciudad en caso de emergencia ${ }^{103}$.

Por consiguiente, en un momento de grave peligro, tanto para Corduba como para Munda, es plausible que sus decuriones intervinieran activamente en la defensa de la ciudad, posiblemente promoviendo la creación de milicias ciudadanas - ¿hubo entre ellas alguna unidad de honderos? - y asumiendo lógicamente el gasto de su equipamiento y armamento. En ese contexto, es posible pensar que se hubieran hecho fabricar proyectiles que con una leyenda $d$ (ecreto) $d($ ecurionum) certificaran el

${ }^{101}$ Urs., 103: "Quicumque in col(onia) Genet(iva) IIvir praef(ectus)ve i(ure) d(icundo) praerit, is colon(os) incolasque contributos quocumque tempore colon(iae) fin(ium) defendendorum causa armatos educere decurio(nes) cen(suerint), quot m(aior) p(ars), qui tum aderunt, decreverint, id e(i) s(ine) f(raude) s(ua) f(acere) 1(iceto). Isque IIvir aut quem IIvir armatis praefecerit idem ius eademque animadversio esto, uti tr(ibuno) mil(itum) p(opuli) R(omani) est, itque e(i) s(ine) f(raude) s(ua) f(acere) 1(iceto) i(us) p(otestas) que e(sto), dum it quot m(aior) $\mathrm{p}$ (ars) decurionum decreverit, qui tum aderunt, fiat" (texto según A.U. Stylow, en La lex Ursonensis: estudio y edición crítica, Studia Historica 15, 1997, 269-301, esp.282-283). Cf. A. D’Ors, Epigrafía jurídica de la España romana, Madrid 1953, 234-235; J. González, Bronces jurídicos romanos de Andalucía, Sevilla 1990, 35. Acerca de la expresión incolae contributi, E. García Fernández, "Incolae contributi y la lex Ursonensis", Studia Historica 15, 171-180. Sobre el tumultus en las ciudades provinciales, C. González Román, "La no ciudad en la Bética", en C. González Román - Á. Padilla Arroba (eds.), Estudios sobre las ciudades de la Bética, Granada 2002, 210: además del citado artículo 103 de la lex Ursonensis, en una inscripción de Castulo se menciona una Cohors Servia Iuvenalium que estaría dedicada a la vigilancia del territorio de esta ciudad (CIL II $3272=$ CILA Jaén 93). En relación con la defensa de una colonia, véase asimismo ILS 6882. Sobre el funcionamiento del senado municipal, R. Mentxaka, El senado municipal en la Bética hispana a la luz de la lex Irnitana, Vitoria 1993.

${ }^{102}$ Así lo piensa García Fernández, "Incolae contributi" (cit. n.101), 178-179, quien considera que esa cláusula para organizar militarmente a la población para proteger el territorio de la ciudad no estaba justificada en una colonia en el sur de Hispania a mediados del siglo I a.C.

${ }^{103} \mathrm{Al}$ respecto, M P. García-Bellido, "La historia de la colonia Lepida-Celsa según sus documentos numismáticos: su ceca imperial", en F. Pina Polo (coord.), Ciudad y romanización en el valle medio del Ebro (siglos II-I a.C.), AEspA 76 (2003) 279. 
respaldo del principal órgano de gobierno de la colonia a una intervención militar que suponía en la práctica la toma de partido a favor de los pompeyanos.

La mención de la decisión de los decuriones en los proyectiles podía asimismo estar justificada complementariamente por la más que probable utilización de fondos públicos en la fabricación de las glandes, puesto que, como es sabido, las finanzas de la ciudad estaban bajo el control del ordo decurionum. El plomo era un metal valioso, que era utilizado en una ciudad para diversos usos públicos, en particular en toda la red existente para el suministro de agua en el interior de las poblaciones (fabricación y conservación de tuberías, etc.), así como también en el ámbito de la construcción (grapas usadas para la unión de sillares en la construcción de edificios, ensamblaje de tambores de columnas, etc.), en esculturas como material de relleno, ponderales, etc. ${ }^{104}$ Es posible por lo tanto que existiera en una ciudad un depósito de reserva de plomo para ser usado en caso de necesidad ${ }^{105}$. Si tal plomo hubiera de ser utilizado para otros menesteres, como por ejemplo la fabricación excepcional de proyectiles, no hay duda de que requeriría la aquiescencia de los decuriones. Plinio, que escribió su Naturalis Historia unos cien años después de la batalla de Munda, afirma que el precio de una libra de plomo (327 gramos) era de siete denarios ${ }^{106}$. Aunque obviamente el precio del plomo no sería exactamente el mismo un siglo antes, el dato proporcionado por el autor latino sirve para hacerse una idea del valor del metal. Las diecinueve glandes con la inscripción $d(-) d(-)$ que aquí presentamos pesaban en total 971 gramos, es decir, casi tres libras. Eso quiere decir que, como promedio, el coste de cada glans podría estar próximo a un denario de acuerdo con el precio apuntado por Plinio. Naturalmente es imposible saber cuántos proyectiles pudieron ser fabricados en Munda (o en Corduba) si nuestra hipótesis es correcta, pero es razonable pensar que serían cientos o quizá miles. Eso supondría una importante inversión de dinero público, que con toda pro-

\footnotetext{
${ }^{104}$ Sobre el uso del plomo véase H. Schwerteck, s.v. "Blei", en H. Cancik - H. Schneider (eds.), Der Neue Pauly. Enzyklopädie der Antike, vol.2, Stuttgart-Weimar 1997, 707709; A.I. Cano Ortiz - J. Acero Pérez, "Los usos del plomo en la ingeniería hidráulica romana. El caso de Augusta Emerita", en Mérida excavaciones Arqueológicas. Memoria 7, 2004, 381-396, con bibliografía suplementaria.

${ }^{105}$ Sobre la importancia para el Estado romano de tener depósitos de plomo para los servicios públicos, véase $\mathrm{Cl}$. Domergue, "L'État romain et le commerce des métaux à la fin de la République et sous le Haut-Empire", en J. Andreau et alii (dir.), Économie antique. Les échanges dans l'Antiquité: le rôle de l'État, St.-Bertrand de Comminges 1994, 99-113, esp.101102. Cf. Frontin., aq., 118,4: "Caesaris familia ex fisco accipit commoda, unde et omne plumbum et omnes impensae ad ductus et castella et lacus pertinentes erogantur".

${ }^{106}$ Plin., n.h., XXXIV 161.
}

babilidad debería ser autorizada por el ordo decurionum.

En definitiva, aunque somos conscientes de que ésta no es en absoluto la única hipótesis posible, a la espera de que puedan aparecer otras piezas que ofrezcan paralelos para éstas nos parece plausible que la leyenda $d(-) d(-)$ de las glandes objeto de estudio pueda significar d(ecreto) d(ecurionum) y, de ser así, los decuriones de Corduba o, más probablemente, los de Munda serían en nuestra opinión los únicos posibles promotores. En los meses en los que se desarrolla el bellum Hispaniense, Munda pudo haber sido una colonia inmune, de acuerdo con Plinio, y Corduba una colonia latina, en ambos casos dotadas de una organización política interna materializada de acuerdo con el modelo republicano romano en asambleas, magistrados y senado u ordo decurionum. Por su condición de caput provinciae y por la enorme relevancia que su control tuvo en el devenir de los acontecimientos, Corduba no sería totalmente descartable. Sin embargo, Munda era también una ciudad de gran importancia, puesto que, de acuerdo con Estrabón, que la llama "metrópolis", ostentaba una cierta primacía entre las poblaciones de su entorno ${ }^{107}$. Si los proyectiles proceden en efecto del entorno del campus Mundensis, Munda parecería su lugar de origen más probable, tanto por la proximidad al campo de batalla, como por el posterior asedio de la ciudad por las tropas cesarianas ${ }^{108}$. Si Munda hubiera recibido la condición de colonia de los pompeyanos, sus habitantes - en particular su aristocracia - podrían tener un interés añadido en hacer constar la existencia de un ordo decurionum en la ciudad como medio para reivindicar su estatuto jurídico superior.

\section{Addendum}

Encontrándose el presente trabajo ya en primeras pruebas, apareció el artículo de M. Grünewald - A. Richter, "Zeugen Caesars schwerster Schlacht? Beschriftete andalusische Schleuderbleie aus der Zeit des Zweiten Punischen Krieges und der Kampagne von Munda", ZPE 157 (2006) 261-269, que analiza las mismas glandes que aquí estudiamos, aunque llegando en parte a diferentes conclusiones. La diferencia es que, mientras nuestros colegas alemanes recogen cincuenta y nueve piezas, nosotros presentamos cuarenta y nueve. Es posible que las diez glandes restantes hayan sido puestas a la venta y hayan ido a parar a otros coleccionistas (véase n.3).

Recibido el 26-04-06 Aceptado el 13-06-06

\footnotetext{
${ }^{107}$ Str., III 2,2. Cf. Caballos Rufino, El nuevo bronce de Osuna (cit. n.76), 308.

${ }^{108}$ Vegecio informa de que los fundidores eran utilizados, no sólo en el campo de batalla, sino también para la defensa de una ciudad sitiada (Veget., mil., I 16; IV 22).
} 